\title{
Synthesis and Antifungal Activities of a Series of (1,2-Disubstituted Vinyl)imidazoles
}

\author{
Masaki OGawa, ${ }^{a}$ Hideaki Matsuda, ${ }^{*, a}$ Hiromichi Eto,${ }^{a}$ Takemitsu AsAoKA, ${ }^{a}$ Tadayuki Kuraishi, ${ }^{a}$ Akira IwasA,${ }^{a}$ Toshiaki \\ NAKASHIMA, ${ }^{a}$ and Kentaro YAMAGUCHI ${ }^{b}$
}

Central Research Laboratories, SS Pharmaceutical Co., Ltd., 1143 Nanpeidai, Narita-shi, Chiba 286, Japan and School of Pharmaceutical Sciences, Showa University, ${ }^{b}$ Hatanodai, Shinagawa-ku, Tokyo 142, Japan. Received February 15, 1991

\begin{abstract}
A series of vinylimidazoles containing a hetero atom such as sulfur or oxygen at a $\beta$-position of the vinyl group was prepared and the antifungal activities were tested. It was found that sulfur-substituted derivatives such as $(E)-1-[2-(m e t h y l t h i o)-1-[2-(p e n t y l o x y) p h e n y l]$ ethenyl]-1 $H$-imidazole $(5 a-5)$ and $(E)-1-[1-[2-(h e x y l o x y)$ phenyl]-2(methylthio)ethenyl]-1 $\mathrm{H}$-imidazole $(5 \mathrm{a}-6)$ showed excellent antifungal activities against dermatophytes and yeast cells. The stereochemistry of the hydrochloride salt of 5a-5 was determined by X-ray crystallography. The structure-activity relationships were discussed.
\end{abstract}

Keywords antifungal activity; imidazole; X-ray crystallography; antifungal agent; structure-activity relationships

Imidazole derivatives have been widely investigated as antifungal agents for plant pathogenic fungi and dermatophytes since the late 1970's. ${ }^{1)}$ Some imidazole-based antifungal agents are now clinically used, and these are classified into three general groups on the basis of chemical structures: the arylmethylimidazoles, the arylethylimidazoles and the vinylimidazoles. ${ }^{2)}$ We have synthesized a new series of vinylimidazole derivatives containing a hetero atom such as sulfur or oxygen at a $\beta$-position of the vinyl group in order to obtain more potent and broad spectrum antifungal agents, and found that sulfur-substituted $E$-form derivatives were more active than the others against a variety of fungi including dermatopytes and yeast cells. In these compounds, 5a-5 and 5a-6 showed the most excellent antifungal activities. The minimum inhibitory concentrations (MICs) of both 5a-5 and 5a-6 were Candida albicans $12.5 \mu \mathrm{g} / \mathrm{ml}$, Trichophyton mentagrophytes $0.2 \mu \mathrm{g} / \mathrm{ml}$, Trichophyton tonsurans $0.2 \mu \mathrm{g} / \mathrm{ml}$, Trichophyton rubrum $0.2 \mu \mathrm{g} / \mathrm{ml}$ and Microsporum gypseum $0.2 \mu \mathrm{g} / \mathrm{ml}$ in vitro, respectively. The stereochemistry of the hydrochloride salt of 5a-5 was determined by X-ray crystallography. In this paper, we wish to report the synthesis, characterization and antifungal activities of these synthetic compounds.

Synthesis The preparations of sulfur-substituted vinylimidazoles were carried out by the following method (Chart 1). Treatment of 2-bromo-2'-hydroxyacetophenone (1a) with methylmercaptan in base gave 2'-hydroxy-2(methylthio)acetophenone (2a). The reaction of $\mathbf{2 a}$ with $1,1^{\prime}$-diimidazolyl sulfoxide by the method of Ogata et al. ${ }^{3}$ ) gave two geometric isomers, $(E)$-1-[1-(2-hydroxyphenyl)2-(methylthio)ethenyl]-1 $H$-imidazole (3a) and its $Z$-isomer (4a) in the ratio of about $5: 1$, which were separated by column chromatography. Ogata et al. ${ }^{4)}$ reported that the chemical shifts of the vinyl protons of $E$ - and $Z-1-[1-$ (2-hydroxyphenyl)-2-methylvinyl]-1 $H$-imidazole were 6.01 and $6.28 \mathrm{ppm}$, respectively. Because the chemical shifts of the vinyl protons of $\mathbf{3 a}$ and $\mathbf{4 a}$ were 6.77 and 7.08 , we presumed the configurations of the two isomers to be $E$ and $Z$, respectively. In the same manner as above, $3 \mathbf{b}-\mathbf{f}$ ( $E$-isomers) and $\mathbf{4 b}-\mathbf{f}$ ( $Z$-isomers) were also prepared in the ratio of about $5: 1$. Equilibrium mixture of $\mathbf{3 a}$ and $\mathbf{4 a}$ was obtained by heating, and their ratio was about $2: 3$ by

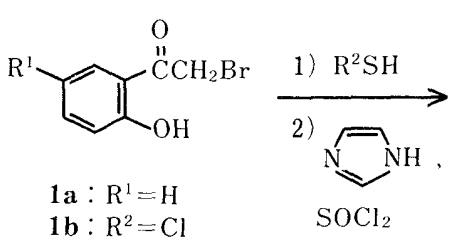

la: $\mathrm{R}^{1}=\mathrm{H}$ 1b: $\mathrm{R}^{2}=\mathrm{Cl}$

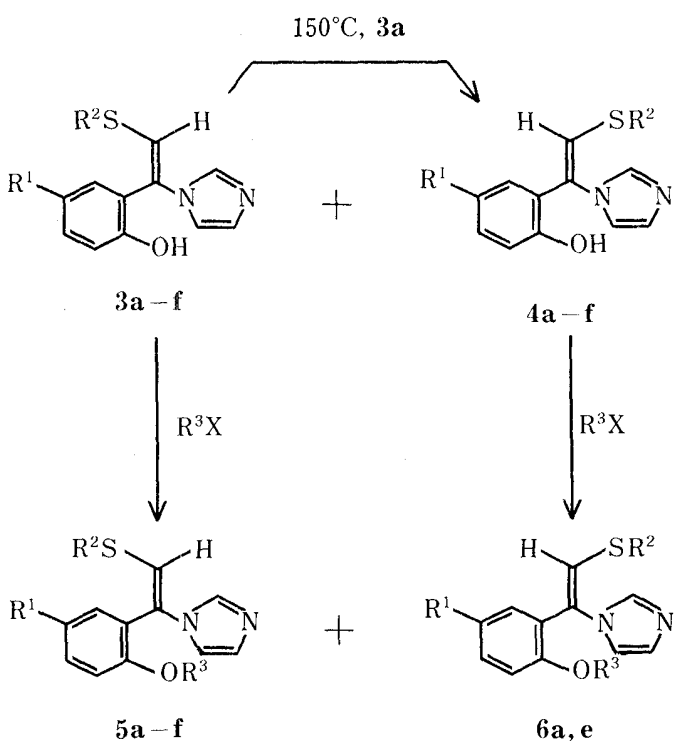

$\mathbf{a}: \mathrm{R}^{1}=\mathrm{H}, \mathrm{R}^{2}=\mathrm{Me} \quad \mathbf{b}: \mathrm{R}^{1}=\mathrm{H}, \mathrm{R}^{2}=\mathrm{Et} \quad \mathbf{c}: \mathrm{R}^{1}=\mathrm{H}, \mathrm{R}^{2}=\mathrm{Pr} \quad \mathbf{d}: \mathrm{R}^{1}=\mathrm{H}, \mathrm{R}^{2}=\mathrm{Bu} \quad \mathbf{e}: \mathrm{R}^{1}=\mathrm{H}, \mathrm{R}^{2}=\mathrm{Ph} \quad \mathbf{f}: \mathrm{R}^{1}=\mathrm{Cl}, \mathrm{R}^{2}=\mathrm{Me}$

Chart 1 


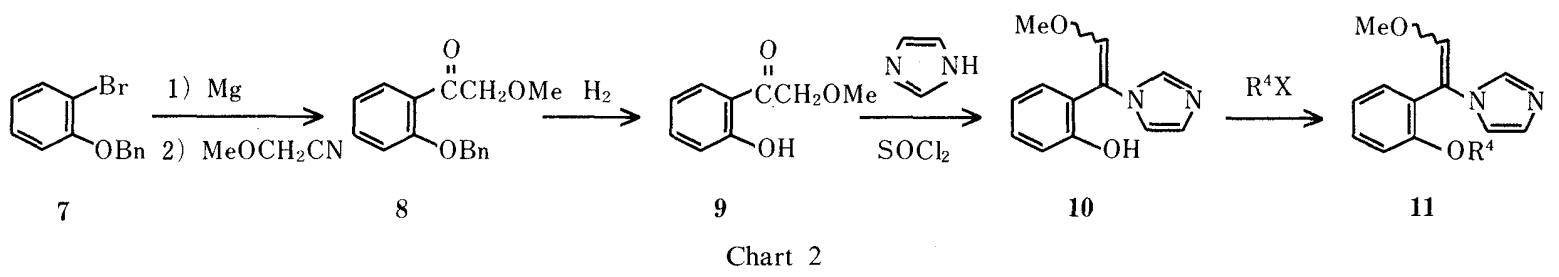

TABLE I. Structures and Antifungal Activities of 5

\begin{tabular}{|c|c|c|c|c|c|c|c|c|c|c|}
\hline No. & $\mathrm{R}^{1}$ & $\mathrm{R}^{2}$ & $\mathrm{R}^{3}$ & Formula & HRMS Caled (Found) & C. albi & T. menta & $\begin{array}{c}\operatorname{MIC}(\mu \mathrm{g} / \mathrm{ml})^{a)} \\
\text { T. tons }\end{array}$ & T. rub & M. $g y p$ \\
\hline $5 a-1$ & $\mathrm{H}$ & $\mathrm{Me}$ & $\mathrm{Me}$ & $\mathrm{C}_{13} \mathrm{H}_{14} \mathrm{~N}_{2} \mathrm{OS}$ & $246.0827(246.0828)$ & $>25$ & 12.5 & 3.12 & 1.56 & 12.5 \\
\hline $5 \mathbf{a}-2$ & $\mathrm{H}$ & $\mathrm{Me}$ & Et & $\mathrm{C}_{14} \mathrm{H}_{16} \mathrm{~N}_{2} \mathrm{OS}$ & $260.0983(260.1014)$ & $>25$ & 1.56 & 0.78 & 0.39 & 3.12 \\
\hline $5 \mathbf{a}-3$ & $\mathrm{H}$ & $\mathrm{Me}$ & $\operatorname{Pr}$ & $\mathrm{C}_{15} \mathrm{H}_{18} \mathrm{~N}_{2} \mathrm{OS}$ & $274.1139(274.1158)$ & $>25$ & 0.78 & 0.39 & 0.39 & 1.56 \\
\hline $5 \mathbf{a}-4$ & $\mathrm{H}$ & $\mathrm{Me}$ & $\mathrm{Bu}$ & $\mathrm{C}_{16} \mathrm{H}_{20} \mathrm{~N}_{2} \mathrm{OS}$ & $288.1296(288.1306)$ & $>25$ & 0.20 & $<0.20$ & $<0.20$ & 0.20 \\
\hline $\mathbf{5 a}-5$ & $\mathrm{H}$ & $\mathrm{Me}$ & Pen & $\mathrm{C}_{17} \mathrm{H}_{22} \mathrm{~N}_{2} \mathrm{OS}$ & $302.1453(302.1501)$ & 12.5 & $<0.20$ & $<0.20$ & $<0.20$ & $<0.20$ \\
\hline $5 \mathbf{a}-6$ & $\mathrm{H}$ & $\mathrm{Me}$ & Hex & $\mathrm{C}_{18} \mathrm{H}_{24} \mathrm{~N}_{2} \mathrm{OS}$ & $316.1609(316.1568)$ & 12.5 & $<0.20$ & $<0.20$ & $<0.20$ & $<0.20$ \\
\hline $\mathbf{5 a}-7$ & $\mathrm{H}$ & $\mathrm{Me}$ & Heptyl & $\mathrm{C}_{19} \mathrm{H}_{26} \mathrm{~N}_{2} \mathrm{OS}$ & $330.1766(330.1730)$ & 25 & $<0.20$ & $<0.20$ & $<0.20$ & $<0.20$ \\
\hline $5 \mathbf{a}-8$ & $\mathrm{H}$ & $\mathrm{Me}$ & Octyl & $\mathrm{C}_{20} \mathrm{H}_{28} \mathrm{~N}_{2} \mathrm{OS}$ & $344.1922(344.1941)$ & $>25$ & 0.39 & $<0.20$ & $<0.20$ & 3.12 \\
\hline $5 a-9$ & $\mathrm{H}$ & $\mathrm{Me}$ & $\mathrm{Bn}$ & $\mathrm{C}_{19} \mathrm{H}_{18} \mathrm{~N}_{2} \mathrm{OS}$ & $322.1141(322.1122)$ & $>25$ & 1.56 & 0.78 & 1.56 & 3.12 \\
\hline $5 \mathbf{a}-10$ & $\mathrm{H}$ & $\mathrm{Me}$ & $\begin{array}{l}\mathrm{Bn} \\
(2,4-\mathrm{diCl})\end{array}$ & $\mathrm{C}_{19} \mathrm{H}_{16} \mathrm{Cl}_{2} \mathrm{~N}_{2} \mathrm{OS}$ & $390.0359(390.0310)$ & $>25$ & 0.20 & 0.20 & $<0.20$ & 0.78 \\
\hline $5 \mathbf{b}-1$ & $\mathrm{H}$ & Et & $\mathrm{Me}$ & $\mathrm{C}_{14} \mathrm{H}_{16} \mathrm{~N}_{2} \mathrm{OS}$ & $260.0983(260.0953)$ & $>25$ & 12.5 & 6.25 & 6.25 & 25 \\
\hline $5 \mathbf{b}-2$ & $\mathrm{H}$ & Et & Et & $\mathrm{C}_{15} \mathrm{H}_{18} \mathrm{~N}_{2} \mathrm{OS}$ & $274.1139(274.1138)$ & $>25$ & 3.12 & 0.78 & 0.78 & 6.25 \\
\hline $5 \mathbf{b}-3$ & $\mathrm{H}$ & Et & $\operatorname{Pr}$ & $\mathrm{C}_{16} \mathrm{H}_{20} \mathrm{~N}_{2} \mathrm{OS}$ & $288.1296(288.1302)$ & $>25$ & 1.56 & 0.78 & 0.39 & 1.56 \\
\hline $5 \mathbf{b}-4$ & $\mathrm{H}$ & Et & $\mathrm{Bu}$ & $\mathrm{C}_{17} \mathrm{H}_{22} \mathrm{~N}_{2} \mathrm{OS}$ & $302.1453(302.1513)$ & 25 & 0.39 & 0.20 & $<0.20$ & 0.78 \\
\hline $5 \mathbf{b}-5$ & $\mathrm{H}$ & Et & Pen & $\mathrm{C}_{18} \mathrm{H}_{24} \mathrm{~N}_{2} \mathrm{OS}$ & $316.1609(316.1615)$ & 25 & $<0.20$ & $<0.20$ & $<0.20$ & $<0.20$ \\
\hline $5 \mathbf{b}-6$ & $\mathrm{H}$ & Et & Hex & $\mathrm{C}_{19} \mathrm{H}_{26} \mathrm{~N}_{2} \mathrm{OS}$ & $330.1766(330.1758)$ & 25 & 0.39 & $<0.20$ & $<0.20$ & 0.78 \\
\hline $5 \mathbf{b}-7$ & $\mathrm{H}$ & $\mathrm{Et}$ & Heptyl & $\mathrm{C}_{20} \mathrm{H}_{28} \mathrm{~N}_{2} \mathrm{OS}$ & $344.1922(344.1970)$ & $>25$ & 1.56 & 0.20 & 0.20 & 3.12 \\
\hline $5 c-1$ & $\mathrm{H}$ & $\operatorname{Pr}$ & $\mathrm{Me}$ & $\mathrm{C}_{15} \mathrm{H}_{18} \mathrm{~N}_{2} \mathrm{OS}$ & $274.1140(274.1092)$ & $>25$ & 6.25 & 3.12 & 3.12 & 6.25 \\
\hline $5 c-2$ & $\mathrm{H}$ & $\operatorname{Pr}$ & Et & $\mathrm{C}_{16} \mathrm{H}_{20} \mathrm{~N}_{2} \mathrm{OS}$ & $288.1296(288.1274)$ & $>25$ & 1.56 & 0.78 & 0.78 & 1.56 \\
\hline $5 c-3$ & $\mathrm{H}$ & $\operatorname{Pr}$ & $\operatorname{Pr}$ & $\mathrm{C}_{17} \mathrm{H}_{22} \mathrm{~N}_{2} \mathrm{OS}$ & $302.1453(302.1444)$ & 12.5 & 0.20 & 0.20 & $<0.20$ & 0.39 \\
\hline $5 c-4$ & $\mathrm{H}$ & $\operatorname{Pr}$ & $\mathrm{Bu}$ & $\mathrm{C}_{18} \mathrm{H}_{24} \mathrm{~N}_{2} \mathrm{OS}$ & $316.1609(316.1562)$ & 12.5 & $<0.20$ & 0.20 & $<0.20$ & $<0.20$ \\
\hline $5 c-5$ & $\mathrm{H}$ & $\operatorname{Pr}$ & Pen & $\mathrm{C}_{19} \mathrm{H}_{26} \mathrm{~N}_{2} \mathrm{OS}$ & $330.1766(330.1806)$ & 12.5 & $<0.20$ & $<0.20$ & 0.20 & 0.20 \\
\hline $5 d-1$ & $\mathrm{H}$ & $\mathrm{Bu}$ & $\mathrm{Me}$ & $\mathrm{C}_{16} \mathrm{H}_{20} \mathrm{~N}_{2} \mathrm{OS}$ & $288.1296(288.1340)$ & 25 & 3.12 & 0.78 & 1.56 & 6.25 \\
\hline $5 d-2$ & $\mathrm{H}$ & $\mathrm{Bu}$ & Et & $\mathrm{C}_{17} \mathrm{H}_{22} \mathrm{~N}_{2} \mathrm{OS}$ & $302.1453(302.1431)$ & 25 & 0.20 & $<0.20$ & $<0.20$ & 0.20 \\
\hline $5 d-3$ & $\mathrm{H}$ & $\mathrm{Bu}$ & $\operatorname{Pr}$ & $\mathrm{C}_{18} \mathrm{H}_{24} \mathrm{~N}_{2} \mathrm{OS}$ & $316.1610(316.1600)$ & 25 & $<0.20$ & $<0.20$ & $<0.20$ & $<0.20$ \\
\hline $5 d-4$ & $\mathrm{H}$ & $\mathrm{Bu}$ & $\mathrm{Bu}$ & $\mathrm{C}_{19} \mathrm{H}_{26} \mathrm{~N}_{2} \mathrm{OS}$ & $330.1766(330.1773)$ & 25 & $<0.20$ & $<0.20$ & $<0.20$ & 0.39 \\
\hline $5 d-5$ & $\mathrm{H}$ & $\mathrm{Bu}$ & Pen & $\mathrm{C}_{20} \mathrm{H}_{28} \mathrm{~N}_{2} \mathrm{OS}$ & $344.1922(344.1904)$ & $>25$ & 1.56 & $<0.20$ & 0.20 & 1.56 \\
\hline $5 e-1$ & $\mathrm{H}$ & $\mathrm{Ph}$ & Et & $\mathrm{C}_{19} \mathrm{H}_{18} \mathrm{~N}_{2} \mathrm{OS}$ & $322.1140(322.1095)$ & 25 & 0.78 & 0.78 & 0.39 & 3.12 \\
\hline $5 e-2$ & $\mathrm{H}$ & $\mathrm{Ph}$ & $\operatorname{Pr}$ & $\mathrm{C}_{20} \mathrm{H}_{20} \mathrm{~N}_{2} \mathrm{OS}$ & $336.1296(336.1282)$ & $>25$ & 0.78 & 1.56 & $<0.20$ & 3.12 \\
\hline $5 e-3$ & $\mathrm{H}$ & $\mathrm{Ph}$ & $\mathrm{Bu}$ & $\mathrm{C}_{21} \mathrm{H}_{22} \mathrm{~N}_{2} \mathrm{OS}$ & $350.1453(350.1471)$ & $>25$ & 3.12 & 6.25 & 1.56 & 6.25 \\
\hline $5 f-1$ & $\mathrm{Cl}$ & $\mathrm{Me}$ & $\mathrm{Pr}$ & $\mathrm{C}_{15} \mathrm{H}_{17} \mathrm{ClN}_{2} \mathrm{OS}$ & $308.0750(308.0773)$ & $>25$ & 0.78 & 0.39 & 0.39 & 1.56 \\
\hline $5 f-2$ & $\mathrm{Cl}$ & $\mathrm{Me}$ & $\mathrm{Bu}$ & $\mathrm{C}_{16} \mathrm{H}_{19} \mathrm{CIN}_{2} \mathrm{OS}$ & $322.0907(322.0935)$ & $>25$ & $<0.20$ & $<0.20$ & $<0.20$ & 0.39 \\
\hline $5 f-3$ & $\mathrm{Cl}$ & $\mathrm{Me}$ & Pen & $\mathrm{C}_{17} \mathrm{H}_{21} \mathrm{ClN}_{2} \mathrm{OS}$ & $336.1064(336.1016)$ & $>25$ & 0.20 & $<0.20$ & $<0.20$ & 1.56 \\
\hline
\end{tabular}

a) C. albi: Candida albicans NHL 4019, T. menta: Trichophyton mentagrophytes QM 248, T. tons: Trichophyton tonsurans IFO 5928, T. rub: Trichophyton rubrum NHL J, M. gyp: Microsporum gypseum IFO 8231.

high performance liquid chromatography (HPLC). To get both alkylated derivatives of $\mathbf{3 a}$ and $\mathbf{4 a}$, the minor product 4a was also prepared from 3a. Heating of $\mathbf{3 a}$ in diethylene glycol dimethyl ether at reflux temperature, followed by recrystallization, gave $\mathbf{4 a}$ in $34 \%$ yield. Treatment of $\mathbf{3 a}$ and $4 \mathbf{a}$ with alkyl halides in the presence of alkali gave 5a-1-10 and 6a-1-3 in moderate yields, respectively. The stereochemistry of $\mathbf{5 a}$ was confirmed by X-ray crystallography of its hydrochloride salt (Experimental section). Treatment of $\mathbf{3 b}-\mathbf{e}$ and $\mathbf{4 e}$ with alkyl halides in the presence of alkali also gave $5 \mathbf{b}-\mathbf{e}(E$-isomers $)$ and $\mathbf{6 e}$ ( $Z$-isomers), respectively. The derivatives 5 f-1-3, which were substituted by the chloro group at the 5 position of the benzene ring, were also prepared.

Oxygen-substituted vinylimidazoles were obtained by the following method (Chart 2). Treatment of 2-(benzyloxy)phenylmagnesium bromide with methoxyacetonitrile in tetrahydrofuran (THF) gave 2'-benzyloxy-2-methoxyace- tophenone (8) in 57\% yield. Reduction of $\mathbf{8}$ with $\mathrm{Pd}$ catalyst under hydrogen atmosphere gave 2'-hydroxy-2methoxyacetophenone (9) in a quantitative yield. The reaction of 9 with $1,1^{\prime}$-diimidazolyl sulfoxide gave the single product 10 in $72 \%$ yield. Treatment of 10 with alkyl halides in the presence of alkali gave its $O$-alkyl derivatives (11-1-4).

\section{Results and Discussion}

The antifungal activities of the compounds in this study are summarized in Tables I (5-series), II (6-series), III (11-series). In the series of (E)-2-methylsulfides (5a-1-10), 5a-5 and 5a-6 were found to be most active against both dermatophytes and yeast cells. In this series, $2^{\prime}$-O $O$-benzyl derivatives $(\mathbf{5} \mathbf{a}-9, \mathbf{5 a}-10)$ were less active than corresponding $2 '-O$-pentyl $(\mathbf{5 a}-5)$ or $2^{\prime}-O$-hexyl (5a-6) derivatives.

In the series of (E)-2-ethylsulfinyl (5b-1-7), $(E)$-2-propylsulfinyl (5c-1-5) and (E)-2-butylsulfinyl (5d-1-5) de- 
TABLE II. Structures and Antifungal Activities of 6

\begin{tabular}{|c|c|c|c|c|c|c|c|c|c|c|}
\hline No. & $\mathrm{R}^{1}$ & $\mathrm{R}^{2}$ & $\mathrm{R}^{3}$ & Formula & HRMS Calcd (Found) & C. albi & T. menta & $\begin{array}{c}\text { MIC }(\mu \mathrm{g} / \mathrm{ml})^{a)} \\
\text { T. tons }\end{array}$ & T. rub & $M . g y p$ \\
\hline $6 a-1$ & $\mathrm{H}$ & $\mathrm{Me}$ & $\mathrm{Bu}$ & $\mathrm{C}_{16} \mathrm{H}_{20} \mathrm{~N}_{2} \mathrm{OS}$ & $288.1297(288.1347)$ & 25 & 0.78 & 0.39 & 0.39 & 0.78 \\
\hline $6 a-2$ & $\mathrm{H}$ & $\mathrm{Me}$ & Pen & $\mathrm{C}_{17} \mathrm{H}_{22} \mathrm{~N}_{2} \mathrm{OS}$ & $302.1453(302.1497)$ & 25 & $<0.20$ & $<0.20$ & $<0.20$ & 0.39 \\
\hline $6 \mathbf{a}-3$ & $\mathrm{H}$ & $\mathrm{Me}$ & Hex & $\mathrm{C}_{18} \mathrm{H}_{24} \mathrm{~N}_{2} \mathrm{OS}$ & $316.1609(316.1583)$ & 25 & $<0.20$ & $<0.20$ & $<0.20$ & 0.39 \\
\hline $6 e-1$ & $\mathrm{H}$ & $\mathrm{Ph}$ & Et & $\mathrm{C}_{19} \mathrm{H}_{18} \mathrm{~N}_{2} \mathrm{OS}$ & $322.1139(322.1170)$ & $>25$ & 6.25 & $>25$ & 3.12 & $>25$ \\
\hline $6 e-2$ & $\mathrm{H}$ & $\mathrm{Ph}$ & $\operatorname{Pr}$ & $\mathrm{C}_{20} \mathrm{H}_{20} \mathrm{~N}_{2} \mathrm{OS}$ & $336.1297(336.1301)$ & $>25$ & 6.25 & 6.25 & 6.12 & 12.5 \\
\hline $6 e-3$ & $\mathrm{H}$ & $\mathrm{Ph}$ & $\mathrm{Bu}$ & $\mathrm{C}_{21} \mathrm{H}_{22} \mathrm{~N}_{2} \mathrm{OS}$ & $350.1453(350.1457)$ & $>25$ & $>25$ & $>25$ & $>25$ & $>25$ \\
\hline
\end{tabular}

a) C. albi: Candida albicans NHL 4019, T. menta: Trichophyton mentagrophytes QM 248, T. tons: Trichophyton tonsurans IFO 5928, T. rub: Trichophyton rubrum NHL J, M. gyp: Microsporum gypseum IFO 8231.

TABLE III. Structures and Antifungal Activities of $\mathbf{1 1}$

\begin{tabular}{|c|c|c|c|c|c|c|c|c|}
\hline No. & $\mathrm{R}^{4}$ & Formula & HRMS Calcd (Found) & C. albi & T. menta & $\begin{array}{c}\mathrm{MIC}(\mu \mathrm{g} / \mathrm{ml})^{a)} \\
\text { T. tons }\end{array}$ & T. rub & M. gyp \\
\hline $11-1$ & $\operatorname{Pr}$ & $\mathrm{C}_{15} \mathrm{H}_{18} \mathrm{~N}_{2} \mathrm{O}_{2}$ & $258.1368(258.1394)$ & $>25$ & 12.5 & 12.5 & 3.12 & 12.5 \\
\hline $11-2$ & $\mathrm{Bu}$ & $\mathrm{C}_{16} \mathrm{H}_{20} \mathrm{~N}_{2} \mathrm{O}_{2}$ & $272.1525(272.1488)$ & $>25$ & 6.25 & 6.25 & 3.12 & 6.25 \\
\hline $11-3$ & Pen & $\mathrm{C}_{17} \mathrm{H}_{22} \mathrm{~N}_{2} \mathrm{O}_{2}$ & $286.1682(286.1662)$ & $>25$ & 3.12 & 3.12 & 0.78 & 3.12 \\
\hline $11-4$ & Hex & $\mathrm{C}_{18} \mathrm{H}_{24} \mathrm{~N}_{2} \mathrm{O}_{2}$ & 300.1838 & $>25$ & 1.56 & 1.56 & 0.78 & 3.12 \\
\hline
\end{tabular}

a) C. albi: Candida albicans NHL 4019, T. menta: Trichophyton mentagrophytes QM 248, T. tons: Trichophyton tonsurans IFO 5928, T. rub: Trichophyton rubrum NHL J, M. gyp: Microsporum gypseum IFO 8231.

TAble IV. Physical Properties and Spectral Data of 3 and 4

\begin{tabular}{|c|c|c|c|c|c|c|c|}
\hline No. & $\mathrm{R}^{1}$ & $\mathrm{R}^{2}$ & Formula & $\begin{array}{l}\text { HRMS Calcd } \\
\text { (Found) }\end{array}$ & $\begin{array}{c}\operatorname{mp}\left({ }^{\circ} \mathrm{C}\right) \\
\left(\text { Recry. solv. }{ }^{a)}\right)\end{array}$ & $\begin{array}{l}\mathrm{IR}\left(\mathrm{cm}^{-1}\right) \\
\quad(\mathrm{KBr})\end{array}$ & NMR: $\delta$ ppm $J(\mathrm{~Hz})\left(\right.$ solv. $\left.^{b)}\right)$ \\
\hline 3a & $\mathrm{H}$ & $\mathrm{Me}$ & $\mathrm{C}_{12} \mathrm{H}_{12} \mathrm{~N}_{2} \mathrm{OS}$ & $\begin{array}{c}232.0670 \\
(232.0640)\end{array}$ & $\begin{array}{l}201-203 \\
(\mathrm{C}, \mathrm{M})\end{array}$ & $\begin{array}{l}1455 \\
1245\end{array}$ & $\begin{array}{l}\text { (S) } 2.30(3 \mathrm{H}, \mathrm{s}, \mathrm{SMe}), 6.77(1 \mathrm{H}, \mathrm{s},=\mathrm{CH}), 6.85-7.40(6 \mathrm{H}, \mathrm{m} \text {, } \\
\text { ArH + imidaC4, C5-H), } 7.74(1 \mathrm{H}, \text { br s, imidaC2-H }), 9.70(1 \mathrm{H} \text {, } \\
\text { br, OH) }\end{array}$ \\
\hline $\mathbf{3 b}$ & $\mathrm{H}$ & Et & $\mathrm{C}_{13} \mathrm{H}_{14} \mathrm{~N}_{2} \mathrm{OS}$ & $\begin{array}{c}246.0827 \\
(246.0851)\end{array}$ & $\begin{array}{l}154-156 \\
(\mathrm{M})\end{array}$ & $\begin{array}{l}1495 \\
1230\end{array}$ & $\begin{array}{l}\text { (D) } 1.30(3 \mathrm{H}, \mathrm{t}, J=7, \mathrm{Me}), 2.74\left(2 \mathrm{H}, \mathrm{q}, J=7, \mathrm{SCH}_{2}\right), 6.42(1 \mathrm{H} \text {, } \\
\text { s, =CH), 6.67-7.38(6H, m, ArH + imidaC4, C5-H), 7.48 }(1 \mathrm{H} \\
\text { br s, imidaC2-H), } 8.80(\mathrm{HH}, \mathrm{br}, \mathrm{OH})\end{array}$ \\
\hline $3 \mathbf{c}$ & $\mathrm{H}$ & $\operatorname{Pr}$ & $\mathrm{C}_{14} \mathrm{H}_{16} \mathrm{~N}_{2} \mathrm{OS}$ & $\begin{array}{c}260.0983 \\
(260.1026)\end{array}$ & $\begin{array}{l}127-128 \\
(\mathrm{M})\end{array}$ & $\begin{array}{l}1495 \\
1230\end{array}$ & $\begin{array}{l}\text { (D) } 0.98(3 \mathrm{H}, \mathrm{t}, J=7, \mathrm{Me}), 1.26-1.85\left(2 \mathrm{H}, \mathrm{m}, \mathrm{CH}_{2}\right), 2.68(2 \mathrm{H}, \\
\left.\text { t, } J=7, \mathrm{SCH}_{2}\right), 6.40(1 \mathrm{H}, \mathrm{s},=\mathrm{CH}), 6.65-7.40(6 \mathrm{H}, \mathrm{m}, \\
\mathrm{ArH}+\text { imidaC4 }, \mathrm{C} 5-\mathrm{H}), 7.46(1 \mathrm{H}, \text { br s, imidaC2-H }), 8.50(1 \mathrm{H}, \\
\text { br, OH })\end{array}$ \\
\hline 3d & $\mathrm{H}$ & $\mathrm{Bu}$ & $\mathrm{C}_{15} \mathrm{H}_{18} \mathrm{~N}_{2} \mathrm{OS}$ & $\begin{array}{c}274.1140 \\
(274.1137)\end{array}$ & $\begin{array}{l}116-118 \\
(\mathrm{EA}, \mathrm{H})\end{array}$ & $\begin{array}{l}1495 \\
1230\end{array}$ & $\begin{array}{l}\text { (D) } 0.88(3 \mathrm{H}, \mathrm{t}, J=7, \mathrm{Me}), 1.02-2.00\left(4 \mathrm{H}, \mathrm{m}, \mathrm{CH}_{2} \times 2\right), 2.69 \\
\left(2 \mathrm{H}, \mathrm{t}, J=7, \mathrm{SCH}_{2}\right), 6.40(1 \mathrm{H}, \mathrm{s},=\mathrm{CH}), 6.6 \mathrm{l}-7.30(6 \mathrm{H}, \mathrm{m}, \\
\mathrm{ArH}+\mathrm{imidaC} 4, \mathrm{C} 5-\mathrm{H}), 7.42(1 \mathrm{H}, \text { br s, imidaC } 2-\mathrm{H}), 8.38(1 \mathrm{H}, \\
\text { br, } \mathrm{OH})\end{array}$ \\
\hline $3 \mathbf{e}$ & $\mathrm{H}$ & $\mathrm{Ph}$ & $\mathrm{C}_{17} \mathrm{H}_{14} \mathrm{~N}_{2} \mathrm{OS}$ & $\begin{array}{l}294.0827 \\
(294.0843)\end{array}$ & $\begin{array}{l}152-154 \\
(\mathrm{M})\end{array}$ & $\begin{array}{l}1450 \\
1230\end{array}$ & $\begin{array}{l}\text { (A) } 6.65(1 \mathrm{H}, \mathrm{s},=\mathrm{CH}), 6.63-7.40(11 \mathrm{H}, \mathrm{m}, \mathrm{ArH}+\text { imidaC } 4 \text {, } \\
\mathrm{C} 5-\mathrm{H}), 7.47(1 \mathrm{H}, \text { br s, imidaC2-H) }\end{array}$ \\
\hline $3 f$ & $\mathrm{Cl}$ & $\mathrm{Me}$ & $\mathrm{C}_{12} \mathrm{H}_{11} \mathrm{ClN}_{2} \mathrm{OS}$ & $\begin{array}{c}266.0281 \\
(266.0310)\end{array}$ & $\begin{array}{l}193-195 \\
(\mathrm{M})\end{array}$ & $\begin{array}{l}1495 \\
1240\end{array}$ & $\begin{array}{l}\text { (S) } 2.33(3 \mathrm{H}, \mathrm{s}, \mathrm{S}-\mathrm{Me}), 6.82(1 \mathrm{H}, \mathrm{s},=\mathrm{CH}), 6.56-7.12(5 \mathrm{H}, \mathrm{m}, \\
\mathrm{ArH}+\mathrm{imidaC} 4, \mathrm{C} 5-\mathrm{H}), 7.60(1 \mathrm{H}, \mathrm{br} \text {, imidaC2-H), } 10.06(1 \mathrm{H}, \\
\mathrm{br}, \mathrm{OH})\end{array}$ \\
\hline $\mathbf{4 a}$ & $\mathrm{H}$ & $\mathrm{Me}$ & $\mathrm{C}_{12} \mathrm{H}_{12} \mathrm{~N}_{2} \mathrm{OS}$ & $\begin{array}{c}232.0670 \\
(232.0623)\end{array}$ & $\begin{array}{l}206-208 \\
(\mathrm{M})\end{array}$ & $\begin{array}{l}1450 \\
1250\end{array}$ & $\begin{array}{l}\text { (S) } 2.39(3 \mathrm{H}, \mathrm{s}, \mathrm{SMe}), 7.08(1 \mathrm{H}, \mathrm{s},=\mathrm{CH}), 6.45-7.24(6 \mathrm{H}, \mathrm{m}, \\
\text { ArH }+ \text { imidaC4, C5-H), } 7.66(1 \mathrm{H}, \mathrm{br} \text {, imidaC2-H), } 10.03(1 \mathrm{H} \text {, } \\
\text { br, OH) }\end{array}$ \\
\hline $4 \mathbf{b}$ & $\mathrm{H}$ & Et & $\mathrm{C}_{13} \mathrm{H}_{14} \mathrm{~N}_{2} \mathrm{OS}$ & $\begin{array}{c}246.0827 \\
(246.0851)\end{array}$ & $\begin{array}{l}195-197 \\
(\mathrm{M})\end{array}$ & $\begin{array}{l}1495 \\
1230\end{array}$ & $\begin{array}{l}\text { (D) } 1.25(3 \mathrm{H}, \mathrm{t}, J=7, \mathrm{Me}), 2.77\left(2 \mathrm{H}, \mathrm{q}, J=7, \mathrm{SCH}_{2}\right), 6.80(1 \mathrm{H}, \\
\mathrm{s},=\mathrm{CH}), 6.75-7.40(6 \mathrm{H}, \mathrm{m}, \mathrm{ArH}+\text { imidaC } 4, \mathrm{C}-\mathrm{H}), 7.68(1 \mathrm{H}, \\
\text { br s, imidaC2-H }), 9.08(1 \mathrm{H}, \mathrm{br}, \mathrm{OH})\end{array}$ \\
\hline $4 c$ & $\mathrm{H}$ & $\operatorname{Pr}$ & $\mathrm{C}_{14} \mathrm{H}_{16} \mathrm{~N}_{2} \mathrm{OS}$ & $\begin{array}{c}260.0984 \\
(260.0936)\end{array}$ & $\begin{array}{l}191-192 \\
(\mathrm{M})\end{array}$ & $\begin{array}{l}1495 \\
1230\end{array}$ & $\begin{array}{l}\text { (D) } 1.01(3 \mathrm{H}, \mathrm{t}, J=7, \mathrm{Me}), 1.20-1.82\left(2 \mathrm{H}, \mathrm{m}, \mathrm{CH}_{2}\right), 2.77(2 \mathrm{H}, \\
\left.\mathrm{t}, J=7, \mathrm{SCH}_{2}\right), 6.80(1 \mathrm{H}, \mathrm{s},=\mathrm{CH}), 6.83-7.40(6 \mathrm{H}, \mathrm{m}, \\
\mathrm{ArH}+\text { imidaC4}, \mathrm{C} 5-\mathrm{H}), 7.69(1 \mathrm{H}, \text { br s, imidaC2-H }), 9.65(1 \mathrm{H}, \\
\text { br, OH) }\end{array}$ \\
\hline $4 d$ & $\mathrm{H}$ & $\mathrm{Bu}$ & $\mathrm{C}_{15} \mathrm{H}_{18} \mathrm{~N}_{2} \mathrm{OS}$ & $\begin{array}{c}274.1140 \\
(274.1093)\end{array}$ & $\begin{array}{l}166-167 \\
(\mathrm{M})\end{array}$ & $\begin{array}{l}1495 \\
1230\end{array}$ & $\begin{array}{l}\text { (D) } 0.88(3 \mathrm{H}, \mathrm{t}, J=7, \mathrm{Me}), 1.08-2.00\left(4 \mathrm{H}, \mathrm{m}, \mathrm{CH}_{2} \times 2\right), 2.76 \\
\left(2 \mathrm{H}, \mathrm{t}, J=7, \mathrm{SCH} \mathrm{H}_{2}\right), 6.82(1 \mathrm{H}, \mathrm{s},=\mathrm{CH}), 6.86-7.37(6 \mathrm{H}, \mathrm{m}, \\
\mathrm{ArH}+\text { imidaC4, C5-H), } 7.65(1 \mathrm{H}, \mathrm{brs} \text {, imidaC2-H }), 8.96(1 \mathrm{H} \text {, } \\
\text { br, OH) }\end{array}$ \\
\hline $4 e$ & $\mathrm{H}$ & $\mathrm{Ph}$ & $\mathrm{C}_{17} \mathrm{H}_{14} \mathrm{~N}_{2} \mathrm{OS}$ & $\begin{array}{l}294.0827 \\
(294.0757)\end{array}$ & $\begin{array}{c}235-237 \\
(\mathrm{M})\end{array}$ & $\begin{array}{l}1440 \\
1245\end{array}$ & $\begin{array}{l}\text { (D) } 6.85(1 \mathrm{H}, \mathrm{s},=\mathrm{CH}), 7.00-7.53(12 \mathrm{H}, \mathrm{m}, \mathrm{ArH}+\text { imidaH }) \text {, } \\
9.26(1 \mathrm{H}, \mathrm{br}, \mathrm{OH})\end{array}$ \\
\hline $4 f$ & $\mathrm{Cl}$ & $\mathrm{Me}$ & $\mathrm{C}_{12} \mathrm{H}_{11} \mathrm{ClN}_{2} \mathrm{OS}$ & $\begin{array}{c}266.0282 \\
(266.0309)\end{array}$ & $\begin{array}{l}250-252 \\
(\mathrm{M})\end{array}$ & $\begin{array}{l}1485 \\
1245\end{array}$ & $\begin{array}{l}\text { (S) } 2.41(3 \mathrm{H}, \mathrm{s}, \mathrm{S}-\mathrm{Me}), 7.10(1 \mathrm{H}, \mathrm{s},=\mathrm{CH}), 6.54-7.33(5 \mathrm{H}, \mathrm{m} \\
\mathrm{ArH}+\text { imidaC4, C5-H), } 7.66(1 \mathrm{H}, \text { br s, imidaC2-H) } 10.35(1 \mathrm{H} \\
\mathrm{br}, \mathrm{OH})\end{array}$ \\
\hline
\end{tabular}


Table V. Physical Properties and Spectral Data of 5, 6 and 11

\begin{tabular}{|c|c|c|c|c|}
\hline No. & $\begin{array}{l}\text { Yield } \\
(\%)\end{array}$ & $\begin{array}{l}\operatorname{mp}\left({ }^{\circ} \mathrm{C}\right) \\
\left.\text { (Recry. solv. }{ }^{a}\right)\end{array}$ & $\begin{array}{l}\text { IR }\left(\mathrm{cm}^{-1}\right) \\
\quad(\mathrm{KBr})\end{array}$ & NMR: $\delta$ ppm $\left(\mathrm{CDCl}_{3}\right) J(\mathrm{~Hz})$ \\
\hline $5 \mathbf{a}-1$ & 38 & Oil & $\begin{array}{l}1490 \\
1250\end{array}$ & $2.28(3 \mathrm{H}, \mathrm{s}, \mathrm{SMe}), 3.68(3 \mathrm{H}, \mathrm{s}, \mathrm{OMe}), 6.38(1 \mathrm{H}, \mathrm{s},=\mathrm{CH}), 6.70-7.50(7 \mathrm{H}, \mathrm{m}, \mathrm{ArH}+\mathrm{imidaH})$ \\
\hline $5 a-2$ & 61 & $\begin{array}{c}96-97 \\
(\text { IPE })\end{array}$ & $\begin{array}{l}1485 \\
1255\end{array}$ & $\begin{array}{l}1.14(3 \mathrm{H}, \mathrm{t}, J=7, \mathrm{Me}), 2.28(3 \mathrm{H}, \mathrm{s}, \mathrm{SMe}), 3.88\left(2 \mathrm{H}, \mathrm{q}, J=7, \mathrm{OCH}_{2}\right), 6.36(1 \mathrm{H}, \mathrm{s},=\mathrm{CH}), 6.70-7.50 \\
(7 \mathrm{H}, \mathrm{m}, \mathrm{ArH}+\mathrm{imidaH})\end{array}$ \\
\hline 5a-3 & 65 & $\begin{array}{l}67-68 \\
(\text { IPE) }\end{array}$ & $\begin{array}{l}1485 \\
1255\end{array}$ & $\begin{array}{l}0.92(3 \mathrm{H}, \mathrm{t}, J=7, \mathrm{Me}), 1.12-1.93\left(2 \mathrm{H}, \mathrm{m}, \mathrm{CH}_{2}\right), 2.28(3 \mathrm{H}, \mathrm{s}, \mathrm{SMe}), 3.85\left(2 \mathrm{H}, \mathrm{t}, J=7, \mathrm{OCH}_{2}\right), \\
6.36(1 \mathrm{H}, \mathrm{s},=\mathrm{CH}), 6.70-7.50(7 \mathrm{H}, \mathrm{m}, \mathrm{ArH}+\mathrm{imidaH})\end{array}$ \\
\hline $5 a-4$ & 67 & $\begin{array}{l}63-65 \\
(\mathrm{IPE})\end{array}$ & $\begin{array}{l}1485 \\
1255\end{array}$ & $\begin{array}{l}0.86(3 \mathrm{H}, \mathrm{t}, J=7, \mathrm{Me}), 1.00-1.70\left(4 \mathrm{H}, \mathrm{m}, \mathrm{CH}_{2} \times 2\right), 2.28(3 \mathrm{H}, \mathrm{s}, \mathrm{SMe}), 3.83\left(2 \mathrm{H}, \mathrm{t}, J=7, \mathrm{OCH}_{2}\right) \\
6.36(1 \mathrm{H}, \mathrm{s},=\mathrm{CH}), 6.70-7.50(7 \mathrm{H}, \mathrm{m}, \mathrm{ArH}+\mathrm{imidaH})\end{array}$ \\
\hline $\mathbf{5 a - 5}$ & 56 & $37-39$ & $\begin{array}{l}1485 \\
1250\end{array}$ & $\begin{array}{l}0.86(3 \mathrm{H}, \mathrm{t}, J=7, \mathrm{Me}), 1.00-1.72\left(6 \mathrm{H}, \mathrm{m}, \mathrm{CH}_{2} \times 3\right), 2.28(3 \mathrm{H}, \mathrm{s}, \mathrm{SMe}), 3.80\left(2 \mathrm{H}, \mathrm{t}, J=7, \mathrm{OCH}_{2}\right), \\
6.36(1 \mathrm{H}, \mathrm{s},=\mathrm{CH}), 6.70-7.50(7 \mathrm{H}, \mathrm{m}, \mathrm{ArH}+\mathrm{imidaH})\end{array}$ \\
\hline $5 a-6$ & 50 & $\begin{array}{l}65-67 \\
(\text { IPE) }\end{array}$ & $\begin{array}{l}1485 \\
1235\end{array}$ & $\begin{array}{l}0.86(3 \mathrm{H}, \mathrm{t}, J=7, \mathrm{Me}), 1.00-1.70\left(8 \mathrm{H}, \mathrm{m}, \mathrm{CH}_{2} \times 4\right), 2.28(3 \mathrm{H}, \mathrm{s}, \mathrm{SMe}), 3.80\left(2 \mathrm{H}, \mathrm{t}, J=7, \mathrm{OCH}_{2}\right), \\
6.36(1 \mathrm{H}, \mathrm{s},=\mathrm{CH}), 6.70-7.50(7 \mathrm{H}, \mathrm{m}, \mathrm{ArH}+\mathrm{imidaH})\end{array}$ \\
\hline $5 a-7$ & 63 & $\begin{array}{l}67-69 \\
(\text { IPE })\end{array}$ & $\begin{array}{l}1485 \\
1230\end{array}$ & $\begin{array}{l}0.86(3 \mathrm{H}, \mathrm{t}, J=7, \mathrm{Me}), 1.00-1.70\left(10 \mathrm{H}, \mathrm{m}, \mathrm{CH}_{2} \times 5\right), 2.28(3 \mathrm{H}, \mathrm{s}, \mathrm{SMe}), 3.80\left(2 \mathrm{H}, \mathrm{t}, J=7, \mathrm{OCH}_{2}\right), \\
6.36(1 \mathrm{H}, \mathrm{s},=\mathrm{CH}), 6.70-7.52(7 \mathrm{H}, \mathrm{m}, \mathrm{ArH}+\mathrm{imidaH})\end{array}$ \\
\hline $\mathbf{5 a}-8$ & 68 & $\begin{array}{l}37-38 \\
(\text { IPE) }\end{array}$ & $\begin{array}{l}1480 \\
1230\end{array}$ & $\begin{array}{l}0.86(3 \mathrm{H}, \mathrm{t}, J=7, \mathrm{Me}), 1.00-1.70\left(12 \mathrm{H}, \mathrm{m}, \mathrm{CH}_{2} \times 6\right), 2.28(3 \mathrm{H}, \mathrm{s}, \mathrm{SMe}), 3.80\left(2 \mathrm{H}, \mathrm{t}, J=7, \mathrm{OCH}_{2}\right), \\
6.34(1 \mathrm{H}, \mathrm{s},=\mathrm{CH}), 6.70-7.50(7 \mathrm{H}, \mathrm{m}, \mathrm{ArH}+\mathrm{imidaH})\end{array}$ \\
\hline $5 \mathbf{a}-9$ & 46 & $\begin{array}{l}85-87 \\
(\text { IPE) }\end{array}$ & $\begin{array}{l}1485 \\
1240\end{array}$ & $2.27(3 \mathrm{H}, \mathrm{s}, \mathrm{SMe}), 4.94\left(2 \mathrm{H}, \mathrm{s}, \mathrm{CH}_{2}\right), 6.36(1 \mathrm{H}, \mathrm{s},=\mathrm{CH}), 6.80-7.50(12 \mathrm{H}, \mathrm{m}, \mathrm{ArH}+\mathrm{imidaH})$ \\
\hline $5 a-10$ & 59 & $\begin{array}{l}106-107 \\
(\mathrm{IPE})\end{array}$ & $\begin{array}{l}1490 \\
1245\end{array}$ & $2.28(3 \mathrm{H}, \mathrm{s}, \mathrm{SMe}), 4.95\left(2 \mathrm{H}, \mathrm{s}, \mathrm{CH}_{2}\right), 6.36(1 \mathrm{H}, \mathrm{s},=\mathrm{CH}), 6.80-7.50(10 \mathrm{H}, \mathrm{m}, \mathrm{ArH}+\mathrm{imidaH})$ \\
\hline $5 \mathbf{b}-1$ & 32 & Oil & $\begin{array}{l}1490 \\
1250\end{array}$ & $\begin{array}{l}1.31\left(3 \mathrm{H}, \mathrm{t}, J=7, \mathrm{SCH}_{2} \mathrm{Me}\right), 2.72\left(2 \mathrm{H}, \mathrm{q}, J=7, \mathrm{SCH}_{2}\right), 3.68(3 \mathrm{H}, \mathrm{s}, \mathrm{OMe}), 6.43(1 \mathrm{H}, \mathrm{s},=\mathrm{CH}) \text {, } \\
6.70-7.50(7 \mathrm{H}, \mathrm{m}, \mathrm{ArH}+\mathrm{imidaH})\end{array}$ \\
\hline $5 \mathbf{b}-2$ & 63 & $\begin{array}{l}79-80 \\
(\mathrm{IPE})\end{array}$ & $\begin{array}{l}1485 \\
1245\end{array}$ & $\begin{array}{l}1.14(3 \mathrm{H}, \mathrm{t}, J=7, \mathrm{Me}), 1.31\left(3 \mathrm{H}, \mathrm{t}, J=7, \mathrm{SCH}_{2} \mathrm{Me}\right), 2.72\left(2 \mathrm{H}, \mathrm{q}, \mathrm{SCH}_{2}\right), 3.88\left(2 \mathrm{H}, \mathrm{q}, J=7, \mathrm{OCH}_{2}\right) \\
6.40(1 \mathrm{H}, \mathrm{s},=\mathrm{CH}), 6.70-7.50(7 \mathrm{H}, \mathrm{m}, \mathrm{ArH}+\mathrm{imidaH})\end{array}$ \\
\hline $5 b-3$ & 68 & $\begin{array}{l}48-49 \\
(\mathrm{IPE})\end{array}$ & $\begin{array}{l}1490 \\
1250\end{array}$ & $\begin{array}{l}0.83(3 \mathrm{H}, \mathrm{t}, J=7, \mathrm{Me}), 1.32\left(3 \mathrm{H}, \mathrm{t}, J=7, \mathrm{SCH}_{2} \mathrm{Me}\right), 1.20-1.70\left(2 \mathrm{H}, \mathrm{m}, \mathrm{CH}_{2}\right), 2.72(2 \mathrm{H}, \mathrm{q}, J=7 \\
\left.\mathrm{SCH}_{2}\right), 3.82\left(2 \mathrm{H}, \mathrm{t}, J=7, \mathrm{OCH}_{2}\right), 6.40(1 \mathrm{H}, \mathrm{s},=\mathrm{CH}), 6.70-7.65(7 \mathrm{H}, \mathrm{m}, \mathrm{ArH}+\mathrm{imidaH})\end{array}$ \\
\hline $5 \mathbf{b}-4$ & 74 & $33-35$ & $\begin{array}{l}1480 \\
1240\end{array}$ & $\begin{array}{l}0.83(3 \mathrm{H}, \mathrm{t}, J=7, \mathrm{Me}), 1.00-1.70\left(4 \mathrm{H}, \mathrm{m}, \mathrm{CH}_{2} \times 2\right), 1.30\left(3 \mathrm{H}, \mathrm{t}, J=7, \mathrm{SCH}_{2} \mathrm{Me}\right), 2.71(2 \mathrm{H}, \mathrm{q}, \\
\left.J=7, \mathrm{SCH}_{2}\right), 3.82\left(2 \mathrm{H}, \mathrm{t}, J=7, \mathrm{OCH}_{2}\right), 6.39(\mathrm{IH}, \mathrm{s},=\mathrm{CH}), 6.70-7.65(7 \mathrm{H}, \mathrm{m}, \mathrm{ArH}+\mathrm{imidaH})\end{array}$ \\
\hline $5 b-5$ & 66 & $\begin{array}{l}51-52 \\
(\mathrm{IPE})\end{array}$ & $\begin{array}{l}1480 \\
1240\end{array}$ & $\begin{array}{l}0.83(3 \mathrm{H}, \mathrm{t}, J=7, \mathrm{Me}), 1.00-1.70\left(6 \mathrm{H}, \mathrm{m}, \mathrm{CH}_{2} \times 3\right), 1.30\left(3 \mathrm{H}, \mathrm{t}, J=7, \mathrm{SCH}_{2} \mathrm{Me}\right), 2.70(2 \mathrm{H}, \mathrm{q}, \\
\left.J=7, \mathrm{SCH}_{2}\right), 3.80\left(2 \mathrm{H}, \mathrm{t}, J=7, \mathrm{OCH}_{2}\right), 6.39(\mathrm{lH}, \mathrm{s},=\mathrm{CH}), 6.70-7.65(7 \mathrm{H}, \mathrm{m}, \mathrm{ArH}+\mathrm{imidaH})\end{array}$ \\
\hline $5 \mathbf{b}-6$ & 70 & $\begin{array}{l}51-53 \\
(\text { IPE })\end{array}$ & $\begin{array}{l}1485 \\
1245\end{array}$ & $\begin{array}{l}0.83(3 \mathrm{H}, \mathrm{t}, J=7, \mathrm{Me}), 1.00-1.70\left(8 \mathrm{H}, \mathrm{m}, \mathrm{CH}_{2} \times 4\right), 1.32\left(3 \mathrm{H}, \mathrm{t}, J=7, \mathrm{SCH}_{2} \mathrm{Me}\right), 2.71(2 \mathrm{H}, \mathrm{q}, \\
\left.J=7, \mathrm{SCH}_{2}\right), 3.80\left(2 \mathrm{H}, \mathrm{t}, J=7, \mathrm{OCH}_{2}\right), 6.39(\mathrm{lH}, \mathrm{s},=\mathrm{CH}), 6.70-7.65(7 \mathrm{H}, \mathrm{m}, \mathrm{ArH}+\mathrm{imidaH})\end{array}$ \\
\hline $5 b-7$ & 76 & $\begin{array}{l}56-57 \\
(\mathrm{IPE})\end{array}$ & $\begin{array}{l}1490 \\
1250\end{array}$ & $\begin{array}{l}0.81(3 \mathrm{H}, \mathrm{t}, J=7, \mathrm{Me}), 1.00-1.70\left(10 \mathrm{H}, \mathrm{m}, \mathrm{CH}_{2} \times 5\right), 1.31\left(3 \mathrm{H}, \mathrm{t}, J=7, \mathrm{SCH}_{2} \mathrm{Me}\right), 2.70(2 \mathrm{H}, \mathrm{q}, \\
\left.J=7, \mathrm{SCH}_{2}\right), 3.80\left(2 \mathrm{H}, \mathrm{t}, J=7, \mathrm{OCH}_{2}\right), 6.40(\mathrm{HH}, \mathrm{s},=\mathrm{CH}), 6.70-7.65(7 \mathrm{H}, \mathrm{m}, \mathrm{ArH}+\mathrm{imidaH})\end{array}$ \\
\hline $5 c-1$ & 35 & $\begin{array}{l}71-72 \\
(\text { IPE })\end{array}$ & $\begin{array}{l}1490 \\
1250\end{array}$ & $\begin{array}{l}0.96\left(3 \mathrm{H}, \mathrm{t}, J=7, \mathrm{~S}\left(\mathrm{CH}_{2}\right)_{2} \mathrm{Me}\right), 1.17-2.00\left(2 \mathrm{H}, \mathrm{m}, \mathrm{CH}_{2}\right), 2.64\left(2 \mathrm{H}, \mathrm{t}, J=7, \mathrm{SCH}_{2}\right), 3.66(3 \mathrm{H}, \mathrm{s}, \\
\mathrm{OMe}), 6.38(1 \mathrm{H}, \mathrm{s},=\mathrm{CH}), 6.70-7.70(7 \mathrm{H}, \mathrm{m}, \mathrm{ArH}+\mathrm{imidaH})\end{array}$ \\
\hline $5 c-2$ & 63 & (IPE) & $\begin{array}{l}1485 \\
1245\end{array}$ & $\begin{array}{l}0.99\left(3 \mathrm{H}, \mathrm{t}, J=7, \mathrm{~S}\left(\mathrm{CH}_{2}\right)_{2} \mathrm{Me}\right), 1.14\left(3 \mathrm{H}, \mathrm{t}, J=7, \mathrm{OCH}_{2} \mathrm{Me}\right), 1.18-2.02\left(2 \mathrm{H}, \mathrm{m}, \mathrm{CH}_{2}\right), 2.68(2 \mathrm{H} \\
\left.\mathrm{t}, J=7, \mathrm{SCH}_{2}\right), 3.88\left(2 \mathrm{H}, \mathrm{q}, J=7, \mathrm{OCH}_{2}\right), 6.38(1 \mathrm{H}, \mathrm{s},=\mathrm{CH}), 6.70-7.70(7 \mathrm{H}, \mathrm{m}, \mathrm{ArH}+\mathrm{imidaH})\end{array}$ \\
\hline $5 c-3$ & 58 & Oil & $\begin{array}{l}1485 \\
1245\end{array}$ & $\begin{array}{l}0.70-1.90\left(10 \mathrm{H}, \mathrm{m}, \mathrm{Me} \times 2+\mathrm{CH}_{2} \times 2\right), 2.68\left(2 \mathrm{H}, \mathrm{t}, J=7, \mathrm{SCH}_{2}\right), 3.78\left(2 \mathrm{H}, \mathrm{t}, J=7, \mathrm{OCH}_{2}\right), 6.40 \\
(1 \mathrm{H}, \mathrm{s},=\mathrm{CH}), 6.70-7.70(7 \mathrm{H}, \mathrm{m}, \mathrm{ArH}+\mathrm{imidaH})\end{array}$ \\
\hline $5 c-4$ & 58 & Oil & $\begin{array}{l}1485 \\
1245\end{array}$ & $\begin{array}{l}0.70-2.00\left(12 \mathrm{H}, \mathrm{m}, \mathrm{Me} \times 2+\mathrm{CH}_{2} \times 3\right), 2.68\left(2 \mathrm{H}, \mathrm{t}, J=7, \mathrm{SCH}_{2}\right), 3.78\left(2 \mathrm{H}, \mathrm{t}, J=7, \mathrm{OCH}_{2}\right), 6.40 \\
(1 \mathrm{H}, \mathrm{s},=\mathrm{CH}), 6.70-7.70(7 \mathrm{H}, \mathrm{m}, \mathrm{ArH}+\mathrm{imidaH})\end{array}$ \\
\hline $5 c-5$ & 65 & Oil & $\begin{array}{l}1485 \\
1250\end{array}$ & $\begin{array}{l}0.70-2.00\left(14 \mathrm{H}, \mathrm{m}, \mathrm{Me} \times 2+\mathrm{CH}_{2} \times 4\right), 2.67\left(2 \mathrm{H}, \mathrm{t}, J=7, \mathrm{SCH}_{2}\right), 3.78\left(2 \mathrm{H}, \mathrm{t}, J=7, \mathrm{OCH}_{2}\right), \\
6.40(1 \mathrm{H}, \mathrm{s},=\mathrm{CH}), 6.70-7.70(7 \mathrm{H}, \mathrm{m}, \mathrm{ArH}+\mathrm{imidaH})\end{array}$ \\
\hline 5d-1 & 39 & $\begin{array}{l}72-74 \\
(\text { IPE) }\end{array}$ & $\begin{array}{l}1490 \\
1245\end{array}$ & $\begin{array}{l}0.90\left(3 \mathrm{H}, \mathrm{t}, J=7, \mathrm{~S}\left(\mathrm{CH}_{2}\right)_{3} \mathrm{Me}\right), 1.10-1.80\left(4 \mathrm{H}, \mathrm{m}, \mathrm{CH}_{2} \times 2\right), 2.68\left(2 \mathrm{H}, \mathrm{t}, J=7, \mathrm{SCH}_{2}\right), 3.68(3 \mathrm{H} \\
\mathrm{s}, \mathrm{OMe}), 6.41(1 \mathrm{H}, \mathrm{s},=\mathrm{CH}), 6.70-7.50(7 \mathrm{H}, \mathrm{m}, \mathrm{ArH}+\mathrm{imidaH})\end{array}$ \\
\hline $5 d-2$ & 51 & Oil & $\begin{array}{l}1495 \\
1250\end{array}$ & $\begin{array}{l}0.70-1.80\left(10 \mathrm{H}, \mathrm{m}, \mathrm{Me} \times 2+\mathrm{CH}_{2} \times 2\right), 2.68\left(2 \mathrm{H}, \mathrm{t}, J=7, \mathrm{SCH}_{2}\right), 3.86\left(2 \mathrm{H}, \mathrm{q}, J=7, \mathrm{OCH}_{2}\right), 6.39 \\
(1 \mathrm{H}, \mathrm{s},=\mathrm{CH}), 6.70-7.60(7 \mathrm{H}, \mathrm{m}, \mathrm{ArH}+\mathrm{imidaH})\end{array}$ \\
\hline $5 d-3$ & 48 & Oil & $\begin{array}{l}1490 \\
1250\end{array}$ & $\begin{array}{l}0.70-1.80\left(12 \mathrm{H}, \mathrm{m}, \mathrm{Me} \times 2+\mathrm{CH}_{2} \times 3\right), 2.68\left(2 \mathrm{H}, \mathrm{t}, J=7, \mathrm{SCH}_{2}\right), 3.80\left(2 \mathrm{H}, \mathrm{t}, J=7, \mathrm{OCH}_{2}\right), 6.37 \\
(1 \mathrm{H}, \mathrm{s},=\mathrm{CH}), 6.70-7.60(7 \mathrm{H}, \mathrm{m}, \mathrm{ArH}+\mathrm{imidaH})\end{array}$ \\
\hline $5 d-4$ & 57 & Oil & $\begin{array}{l}1485 \\
1245\end{array}$ & $\begin{array}{l}0.70-1.80\left(14 \mathrm{H}, \mathrm{m}, \mathrm{Me} \times 2+\mathrm{CH}_{2} \times 4\right), 2.68\left(2 \mathrm{H}, \mathrm{t}, J=7, \mathrm{SCH}_{2}\right), 3.80\left(2 \mathrm{H}, \mathrm{t}, J=7, \mathrm{OCH}_{2}\right), 6.37 \\
(1 \mathrm{H}, \mathrm{s},=\mathrm{CH}), 6.70-7.60(7 \mathrm{H}, \mathrm{m}, \mathrm{ArH}+\mathrm{imidaH})\end{array}$ \\
\hline $5 d-5$ & 62 & Oil & $\begin{array}{l}1490 \\
1250\end{array}$ & $\begin{array}{l}0.70-1.80\left(16 \mathrm{H}, \mathrm{m}, \mathrm{Me} \times 2+\mathrm{CH}_{2} \times 5\right), 2.68\left(2 \mathrm{H}, \mathrm{t}, J=7, \mathrm{SCH}_{2}\right), 3.80\left(2 \mathrm{H}, \mathrm{t}, J=7, \mathrm{OCH}_{2}\right), 6.38 \\
(1 \mathrm{H}, \mathrm{s},=\mathrm{CH}), 6.80-7.60(7 \mathrm{H}, \mathrm{m}, \mathrm{ArH}+\mathrm{imidaH})\end{array}$ \\
\hline $5 e-1$ & 65 & Oil & $\begin{array}{l}1480 \\
1230\end{array}$ & $\begin{array}{l}1.12(3 \mathrm{H}, \mathrm{t}, J=7, \mathrm{Me}), 3.77\left(2 \mathrm{H}, \mathrm{q}, J=7, \mathrm{OCH}_{2}\right), 6.42(1 \mathrm{H}, \mathrm{s},=\mathrm{CH}), 6.75-7.65(12 \mathrm{H}, \mathrm{m}, \\
\text { ArH }+ \text { imidaH })\end{array}$ \\
\hline $5 e-2$ & 68 & Oil & $\begin{array}{l}1480 \\
1230\end{array}$ & $\begin{array}{l}0.88(3 \mathrm{H}, \mathrm{t}, J=7, \mathrm{Me}), 1.13-1.94\left(2 \mathrm{H}, \mathrm{m}, \mathrm{CH}_{2}\right), 3.73\left(2 \mathrm{H}, \mathrm{t}, J=7, \mathrm{OCH}_{2}\right), 6.42(1 \mathrm{H}, \mathrm{s},=\mathrm{CH}), \\
6.79-7.58(12 \mathrm{H}, \mathrm{m}, \mathrm{ArH}+\mathrm{imidaH})\end{array}$ \\
\hline $5 e-3$ & 67 & Oil & $\begin{array}{l}1480 \\
1220\end{array}$ & $\begin{array}{l}0.88(3 \mathrm{H}, \mathrm{t}, J=7, \mathrm{Me}), 1.02-1.90\left(4 \mathrm{H}, \mathrm{m}, \mathrm{CH}_{2} \times 2\right), 3.73\left(2 \mathrm{H}, \mathrm{t}, J=7, \mathrm{OCH}_{2}\right), 6.44(1 \mathrm{H}, \mathrm{s},=\mathrm{CH}) \\
6.70-7.55(12 \mathrm{H}, \mathrm{m}, \mathrm{ArH}+\mathrm{imidaH})\end{array}$ \\
\hline $5 f-1$ & 51 & $\begin{array}{l}91-93 \\
(\mathrm{IPE})\end{array}$ & $\begin{array}{l}1490 \\
1245\end{array}$ & $\begin{array}{l}0.88(3 \mathrm{H}, \mathrm{t}, J=7, \mathrm{Me}), 1.15-1.80\left(2 \mathrm{H}, \mathrm{m}, \mathrm{CH}_{2}\right), 2.25(3 \mathrm{H}, \mathrm{s}, \mathrm{SMe}), 3.78\left(2 \mathrm{H}, \mathrm{t}, J=7, \mathrm{OCH}_{2}\right), \\
6.39(1 \mathrm{H}, \mathrm{s},=\mathrm{CH}), 6.70-7.60(6 \mathrm{H}, \mathrm{m}, \mathrm{ArH}+\mathrm{imidaH})\end{array}$ \\
\hline $5 f-2$ & 58 & $\begin{array}{l}46-47 \\
(\mathrm{IPE})\end{array}$ & $\begin{array}{l}1490 \\
1245\end{array}$ & $\begin{array}{l}0.87(3 \mathrm{H}, \mathrm{t}, J=7, \mathrm{Me}), 1.05-1.80\left(4 \mathrm{H}, \mathrm{m}, \mathrm{CH}_{2} \times 2\right), 2.25(3 \mathrm{H}, \mathrm{s}, \mathrm{SMe}), 3.78\left(2 \mathrm{H}, \mathrm{t}, J=7, \mathrm{OCH}_{2}\right), \\
6.38(1 \mathrm{H}, \mathrm{s},=\mathrm{CH}), 6.70-7.60(6 \mathrm{H}, \mathrm{m}, \mathrm{ArH}+\mathrm{imidaH})\end{array}$ \\
\hline $5 f-3$ & 63 & Oil & $\begin{array}{l}1490 \\
1250\end{array}$ & $\begin{array}{l}0.87(3 \mathrm{H}, \mathrm{t}, J=7, \mathrm{Me}), 1.00-1.80\left(6 \mathrm{H}, \mathrm{m}, \mathrm{CH}_{2} \times 2\right), 2.25(3 \mathrm{H}, \mathrm{s}, \mathrm{SMe}), 3.78\left(2 \mathrm{H}, \mathrm{t}, J=7, \mathrm{OCH}_{2}\right), \\
6.36(1 \mathrm{H}, \mathrm{s},=\mathrm{CH}), 6.70-7.60(6 \mathrm{H}, \mathrm{m}, \mathrm{ArH}+\mathrm{imidaH})\end{array}$ \\
\hline
\end{tabular}


TABLE V. (continued)

\begin{tabular}{|c|c|c|c|c|}
\hline No. & $\begin{array}{l}\text { Yield } \\
(\%)\end{array}$ & $\begin{array}{c}\mathrm{mp}\left({ }^{\circ} \mathrm{C}\right) \\
\left(\text { Recry. solv. }{ }^{a}\right)\end{array}$ & $\begin{array}{l}\operatorname{IR}\left(\mathrm{cm}^{-1}\right) \\
\quad(\mathrm{KBr})\end{array}$ & NMR: $\delta$ ppm $\left(\mathrm{CDCl}_{3}\right) J(\mathrm{~Hz})$ \\
\hline $6 a-1$ & 54 & Oil & $\begin{array}{l}1490 \\
1250\end{array}$ & $\begin{array}{l}0.92(3 \mathrm{H}, \mathrm{t}, J=7, \mathrm{Me}), 1.10-1.80\left(4 \mathrm{H}, \mathrm{m}, \mathrm{CH}_{2} \times 2\right), 2.32(3 \mathrm{H}, \mathrm{s}, \mathrm{SMe}), 3.88\left(2 \mathrm{H}, \mathrm{t}, J=7, \mathrm{OCH}_{2}\right), \\
6.74(1 \mathrm{H}, \mathrm{s},=\mathrm{CH}), 6.76-7.40(6 \mathrm{H}, \mathrm{m}, \mathrm{ArH}+\text { imidaC4 }, \mathrm{C} 5-\mathrm{H}), 7.56(1 \mathrm{H}, \mathrm{br}, \text { imidaC2}-\mathrm{H})\end{array}$ \\
\hline $\mathbf{6 a}-2$ & 49 & Oil & $\begin{array}{l}1490 \\
1250\end{array}$ & $\begin{array}{l}0.90(3 \mathrm{H}, \mathrm{t}, J=7, \mathrm{Me}), 1.10-1.80\left(6 \mathrm{H}, \mathrm{m}, \mathrm{CH}_{2} \times 3\right), 2.32(3 \mathrm{H}, \mathrm{s}, \mathrm{SMe}), 3.86\left(2 \mathrm{H}, \mathrm{t}, J=7, \mathrm{OCH}_{2}\right), \\
6.74(1 \mathrm{H}, \mathrm{s},=\mathrm{CH}), 6.76-7.40(6 \mathrm{H}, \mathrm{m}, \mathrm{ArH}+\text { imidaC4, C5-H), } 7.54(1 \mathrm{H}, \mathrm{br} \text { s, imidaC2-H })\end{array}$ \\
\hline 6a-3 & 59 & Oil & $\begin{array}{l}1490 \\
1250\end{array}$ & $\begin{array}{l}0.89(3 \mathrm{H}, \mathrm{t}, J=7, \mathrm{Me}), 1.10-1.80\left(8 \mathrm{H}, \mathrm{m}, \mathrm{CH}_{2} \times 4\right), 2.31(3 \mathrm{H}, \mathrm{s}, \mathrm{SMe}), 3.86\left(2 \mathrm{H}, \mathrm{t}, J=7, \mathrm{OCH}_{2}\right), \\
6.76(1 \mathrm{H}, \mathrm{s},=\mathrm{CH}), 6.75-7.40(6 \mathrm{H}, \mathrm{m}, \mathrm{ArH}+\mathrm{imidaC} 4, \mathrm{C} 5-\mathrm{H}), 7.55(1 \mathrm{H}, \mathrm{br} \text { s, imidaC2-H })\end{array}$ \\
\hline $6 e-1$ & 75 & $\begin{array}{l}96-97 \\
(\text { IPE) }\end{array}$ & $\begin{array}{l}1480 \\
1240\end{array}$ & $\begin{array}{l}1.25(3 \mathrm{H}, \mathrm{t}, J=7, \mathrm{Me}), 3.87\left(2 \mathrm{H}, \mathrm{q}, J=7, \mathrm{OCH}_{2}\right), 6.70-7.50(12 \mathrm{H}, \mathrm{m}, \mathrm{ArH}+\mathrm{imidaC} 4, \mathrm{C} 5-\mathrm{H}), 7.70 \\
(1 \mathrm{H}, \mathrm{br} \mathrm{s}, \text { imidaC2-H })\end{array}$ \\
\hline $6 e-2$ & 61 & $\begin{array}{l}75-76 \\
(\text { IPE })\end{array}$ & $\begin{array}{l}1480 \\
1230\end{array}$ & $\begin{array}{l}0.88(3 \mathrm{H}, \mathrm{t}, J=7, \mathrm{Me}), 1.22-2.00\left(2 \mathrm{H}, \mathrm{m}, \mathrm{CH}_{2}\right), 3.86\left(2 \mathrm{H}, \mathrm{t}, J=7, \mathrm{OCH}_{2}\right), 6.70-7.50(12 \mathrm{H}, \mathrm{m}, \\
\mathrm{ArH}+\mathrm{imidaC} 4, \mathrm{C} 5-\mathrm{H}), 7.70(1 \mathrm{H}, \mathrm{brs} \text {, imidaC2-H) }\end{array}$ \\
\hline $6 e-3$ & 66 & $\begin{array}{l}97-98 \\
\text { (IPE) }\end{array}$ & $\begin{array}{l}1480 \\
1240\end{array}$ & $\begin{array}{l}0.88(3 \mathrm{H}, \mathrm{t}, J=7, \mathrm{Me}), 1.08-1.80\left(4 \mathrm{H}, \mathrm{m}, \mathrm{CH}_{2} \times 2\right), 3.87\left(2 \mathrm{H}, \mathrm{t}, J=7, \mathrm{OCH}_{2}\right), 6.70-7.50(12 \mathrm{H}, \\
\mathrm{m}, \mathrm{ArH}+\text { imidaC } 4, \mathrm{C} 5-\mathrm{H}), 7.70(1 \mathrm{H}, \mathrm{br} \mathrm{s}, \text { imidaC } 2-\mathrm{H})\end{array}$ \\
\hline 11-1 & 54 & Oil & $\begin{array}{l}1450 \\
1240\end{array}$ & $\begin{array}{l}0.90(3 \mathrm{H}, \mathrm{t}, J=7, \mathrm{Me}), 1.20-1.70\left(2 \mathrm{H}, \mathrm{m}, \mathrm{CH}_{2}\right), 3.72(3 \mathrm{H}, \mathrm{s}, \mathrm{OMe}), 3.80\left(2 \mathrm{H}, \mathrm{t}, J=7, \mathrm{OCH}_{2}\right), \\
6.48(1 \mathrm{H}, \mathrm{s},=\mathrm{CH}), 6.70-7.50(6 \mathrm{H}, \mathrm{m}, \mathrm{ArH}+\text { imidaC4, C5-H }), 7.56(1 \mathrm{H}, \mathrm{brs} \text {, imidaC2-H })\end{array}$ \\
\hline $11-2$ & 60 & Oil & $\begin{array}{l}1450 \\
1240\end{array}$ & $\begin{array}{l}0.90(3 \mathrm{H}, \mathrm{t}, J=7, \mathrm{Me}), 1.00-1.70\left(4 \mathrm{H}, \mathrm{m}, \mathrm{CH}_{2} \times 2\right), 3.74(3 \mathrm{H}, \mathrm{s}, \mathrm{OMe}), 3.84\left(2 \mathrm{H}, \mathrm{t}, J=7, \mathrm{OCH}_{2}\right), \\
6.50(1 \mathrm{H}, \mathrm{s},=\mathrm{CH}), 6.70-7.50(6 \mathrm{H}, \mathrm{m}, \mathrm{ArH}+\text { imidaC4 } \mathrm{C} 5-\mathrm{H}), 7.56(1 \mathrm{H}, \mathrm{brs}, \text { imidaC2-H })\end{array}$ \\
\hline 11-3 & 71 & Oil & $\begin{array}{l}1450 \\
1240\end{array}$ & $\begin{array}{l}0.88(3 \mathrm{H}, \mathrm{t}, J=7, \mathrm{Me}), 1.00-1.70\left(6 \mathrm{H}, \mathrm{m}, \mathrm{CH}_{2} \times 3\right), 3.74(3 \mathrm{H}, \mathrm{s}, \mathrm{OMe}), 3.84\left(2 \mathrm{H}, \mathrm{t}, J=7, \mathrm{OCH}_{2}\right), \\
6.50(1 \mathrm{H}, \mathrm{s},=\mathrm{CH}), 6.70-7.50(6 \mathrm{H}, \mathrm{m}, \mathrm{ArH}+\mathrm{imidaC} 4, \mathrm{C} 5-\mathrm{H}), 7.56(1 \mathrm{H}, \mathrm{br} \text { s, imidaC2-H })\end{array}$ \\
\hline $11-4$ & 68 & Oil & $\begin{array}{l}1450 \\
1240\end{array}$ & $\begin{array}{l}0.88(3 \mathrm{H}, \mathrm{t}, J=7, \mathrm{Me}), 1.00-1.70\left(8 \mathrm{H}, \mathrm{m}, \mathrm{CH}_{2} \times 4\right), 3.74(3 \mathrm{H}, \mathrm{s}, \mathrm{OMe}), 3.84\left(2 \mathrm{H}, \mathrm{t}, J=7, \mathrm{OCH}_{2}\right), \\
6.48(1 \mathrm{H}, \mathrm{s},=\mathrm{CH}), 6.70-7.50(6 \mathrm{H}, \mathrm{m}, \mathrm{ArH}+\text { imidaC4 }, \mathrm{C} 5-\mathrm{H}), 7.56(1 \mathrm{H}, \mathrm{s}, \text { imidaC2-H })\end{array}$ \\
\hline
\end{tabular}

a) IPE: isopropyl ether.

TABLE VI. Antifungal Activity of 5a-5, Clotrimazole and Miconazole (MIC: $\mu \mathrm{g} / \mathrm{ml}$ )

\begin{tabular}{|c|c|c|c|c|c|c|}
\hline \multirow{3}{*}{ Organisms } & \multicolumn{6}{|c|}{ Antifungals } \\
\hline & \multicolumn{2}{|c|}{$5 \mathbf{a}-5$} & \multicolumn{2}{|c|}{ Clotrimazole $^{a)}$} & \multicolumn{2}{|c|}{ Miconazole $^{b)}$} \\
\hline & $\begin{array}{l}\text { Without } \\
\text { serum }^{c)}\end{array}$ & $\begin{array}{l}\text { With } 10 \% \\
\text { serum }\end{array}$ & $\begin{array}{l}\text { Without } \\
\text { serum }\end{array}$ & $\begin{array}{l}\text { With } 10 \% \\
\text { serum }\end{array}$ & $\begin{array}{l}\text { Without } \\
\text { serum }\end{array}$ & $\begin{array}{l}\text { With } 10 \% \\
\text { serum }\end{array}$ \\
\hline Candida albicans NHL 4019 & 12.5 & 50 & 25 & 50 & 25 & 100 \\
\hline C. albicans IFO 1060 & 0.39 & 3.12 & 1.56 & 12.5 & 0.39 & 25 \\
\hline Trichophyton mentagrophytes QM 248 & 0.05 & 0.39 & 0.20 & 3.12 & 1.56 & 50 \\
\hline T. tonsurans IFO 5928 & 0.025 & 0.39 & 0.20 & 3.12 & 0.20 & 50 \\
\hline T. rubrum NHL J & 0.025 & 0.20 & 0.39 & 6.25 & 0.20 & 25 \\
\hline Microsporum gypseum IFO 8231 & 0.10 & 3.12 & 0.39 & 6.25 & 6.25 & 50 \\
\hline M. audouini IFO 6074 & 0.05 & 0.39 & 0.20 & 3.12 & 1.56 & 50 \\
\hline
\end{tabular}

a) 1-[(2-Chlorophenyl)diphenylmethyl]-1 $H$-imidazole. b) 1-[2-(2,4-Dichlorophenyl)-2-[(2,4-dichlorophenyl)methoxy]ethyl]-1 $H$-imidazole. c) Horse serum.

rivatives, the most active compound in each series was 5b-5, 5c-4 and 5d-3, respectively. These results showed that the compounds with 6 to 7 carbons, which were the sum of the carbons of $S$-alkyl and $O$-alkyl substituents, were most active in each series of 2-alkylsulfides.

The $Z$-isomers $\mathbf{6 a - 2}$ and $\mathbf{6 a - 3}$ were slightly less active than corresponding $E$-isomers 5a-5 and 5a-6.

In the series of $(E)$-2-phenylsulfides (5e-1-3), 5e-2 was most active. But it was less active than ( $E$ )-2-alkylsulfides $(\mathbf{5 a}-5, \mathbf{5} \mathbf{a}-6, \mathbf{5 b}-4, \mathbf{5}-4$ or $\mathbf{5 d}-3)$, and in this case $Z$-isomers (6e-1-3) were also less active than $E$-isomers (5e-1-3). There was also a similarity observed in the case of 2-methylsulfides. Further, we compared the activities of 2-methylsulfides with chloro substituent at the 5 position of the benzene ring, (5f-1-3), with that of 5a-5. In this case, $\mathbf{5} \mathbf{a}-5$ was also found to be most active.

Next, we compared the activities of 2-methylsulfides (5a) with those of 2-methoxy derivatives (11-1-4) and found that the 5a series was more active than the $\mathbf{1 1}$ series.

In conclusion, (2-sulfinylvinyl)imidazoles showed excellent antifungal activities against dermatophytes and yeast cells, with the activities of 5a-5 and 5a-6 the best of all.

The antifungal activity of $\mathbf{5 a}-5$ in comparison with some known synthetic antifungal agents is shown in Table VI. ${ }^{5 a-e)}$ Against dermatophytes, 5a-5 was more active than the other antifungals, and when the agar was supplemented with $10 \%$ horse serum, ${ }^{6}$ ) the activity of $\mathbf{5 a}-5$ was also more active than the others. The antifungal activity of 5a-6 was equally as active as 5a-5, and further experiments are ongoing.

\section{Experimental}

All melting points were determined on a Yanagimoto micromelting point apparatus and are uncorrected. Infrared (IR) spectra were measured with a JASCO A-102 IR spectrometer. Proton magnetic resonance $\left({ }^{1} \mathrm{H}-\mathrm{NMR}\right)$ was taken on a Hitachi R-24B $(60 \mathrm{MHz})$ or JEOL FX90Q spectrometer $(90 \mathrm{MHz})$. Chemical shifts are expressed in ppm values relative to tetramethylsilane (TMS) as an internal standard: $s=$ singlet, $\mathrm{d}=$ doublet, $\mathrm{t}=$ triplet, $\mathrm{m}=$ multiplet and $\mathrm{br}=$ broad. Positive mass spectra and high-resolution mass spectra (MS) were taken on a JEOL JMX-DX303 mass spectrometer by a direct inlet method. Column chromatography was carried out on silica gel (Wakogel C-200). HPLC was carried out on an apparatus consisting of a Hitachi L-600 pump with a Hitachi L-400 ultraviolet (UV) detector using a Lichrosorb SI 60 
column $(5 \mu \mathrm{m}, 4$ i.d $\times 250 \mathrm{~mm})$ and the solvent system: chloroform $-n-$ hexane-ethanol-acetic acid-triethylamine $(1480: 400: 120: 10: 1 \mathrm{v} / \mathrm{v})$ at a flow rate of $1.5 \mathrm{ml} / \mathrm{min}$. The retention times of $\mathbf{3 a}$ and $\mathbf{4 a}$ were 5.4 , $3.6 \mathrm{~min}$, respectively.

Antifungal Test A susceptibility test for fungi was performed using the agar dilution test method on Sabouraud dextrose agar (SDA). Test samples, which were dissolved in $1 \%$ dimethyl sulfoxide (DMSO), were added to SDA at a final concentration range of 0.05 to $100 \mu \mathrm{g} / \mathrm{ml}$. Inocula suspension, $10^{6} \mathrm{cells} / \mathrm{ml}$, was spotted on the agar surface with a multipoint inoculator. The MIC was defined as the lowest concentration of the sample preventing macroscopically visible growth after incubation at $27^{\circ} \mathrm{C}$ for $3 \mathrm{~d}$ (for yeasts) and for $7 \mathrm{~d}$ (for dermatophytic fungi). The effect of serum on MIC was determined using SDA containing 10\% horse serum.

$(E)-(3 a)$ and $(Z)-1-[1-(2-H y d r o x y p h e n y l)-2-(m e t h y l t h i o) e t h e n y l]-1 H$ imidazole (4a) A solution of $15 \%$ sodium methylmercaptide $(5.45 \mathrm{ml})$ was added to a stirred solution of 2-bromo-2'-hydroxyacetophenone (1a, $2.52 \mathrm{~g}$ ) in methanol $(190 \mathrm{ml})$ in an ice bath. The reaction mixture was stirred for $30 \mathrm{~min}$ at room temperature. The solvent was evaporated under reduced pressure, and the residue was acidified with diluted hydrochloric acid and extracted with ethyl acetate. The organic layer was washed with diluted hydrochloric acid and water, and dried over $\mathrm{MgSO}_{4}$. The solvent was evaporated under reduced pressure, and the residue was chromatographed (chloroform) to give 2'-hydroxy-2-(methylthio)acetophenone $(\mathbf{2 a}, 2.10 \mathrm{~g}, 98 \%)$ as yellow liquid. MS $m / z: 182\left(\mathrm{M}^{+}\right)$.

Thionyl chloride $(2.06 \mathrm{~g})$ was added to a stirred suspension of imidazole $(4.71 \mathrm{~g})$ in dichloromethane $(25 \mathrm{ml})$ in an ice bath. The reaction mixture was stirred for $30 \mathrm{~min}$ at room temperature. Then a solution of $\mathbf{2 a}$ $(2.10 \mathrm{~g})$ in dichloromethane $(5 \mathrm{ml})$ was added to the above solution in an ice bath. The reaction mixture was stirred for $30 \mathrm{~min}$ at room temperature, washed with water and dried over $\mathrm{MgSO}_{4}$. After removal of the solvent under reduced pressure, the residue was chromatographed (chloroform: methanol $=10: 1)$. First, 4a $(0.32 \mathrm{~g}, 12 \%)$ was obtained as colorless needles, and secondly 3a $(1.50 \mathrm{~g}, 56 \%)$ was obtained as colorless prisms.

The series of $\mathbf{3 b}-\mathbf{f}$ and $\mathbf{4 b}-\mathbf{f}$ were prepared in the same manner. The yields were 3b: $48 \%$, 4b: $10 \%$; 3c: $37 \%, 4 c: 7 \%$; 3d: $45 \%, 4 d: 8 \% ; 3 e$ : $31 \%, 4 e: 7 \% ; 3 f: 51 \%$, 4f: $12 \%$ (Table IV).

(Z)-1-[1-(2-Hydroxyphenyl)-2-(methylthio)ethenyl]-1 $\mathrm{H}$-imidazole (4a) 3a $(6.70 \mathrm{~g})$ was suspended in diethylene glycol dimethyl ether $(140 \mathrm{ml})$, and gently refluxed for about $1 \mathrm{~h}$. Then the temperature was kept at $50{ }^{\circ} \mathrm{C}$ with stirring for $1 \mathrm{~h}$. The precipitate was collected, washed with ether and recrystallized from methanol to give $\mathbf{4 a}(2.27 \mathrm{~g}, 34 \%)$

$(E)$-1-[2-(Methylthio)-1-[2-(pentyloxy)phenyl]ethenyl]-1 $\mathrm{H}$-imidazole (5a-5) A solution of $3 \mathrm{a}(1.5 \mathrm{~g}), \mathrm{KOH}(0.51 \mathrm{~g})$ and pentyl bromide $(1.15 \mathrm{~g})$ in dimethylformamide (DMF) $(10 \mathrm{ml})$ was stirred for $3 \mathrm{~h}$ at room temperature. Then the reaction mixture was poured into water and extracted with ether. The organic layer was washed with water and dried over $\mathrm{MgSO}_{4}$. After removal of the solvent under reduced pressure, the residue was chromatographed (chloroform) to give 5a-5 $(1.10 \mathrm{~g}, 56 \%)$ as colorless crystals. MS $m / z: 302\left(\mathrm{M}^{+}\right)$.

The series of $\mathbf{5 a}-\mathbf{f}, \mathbf{6} \mathbf{a}, \mathbf{e}$ and $\mathbf{1 1}$ were also prepared in the same manner (Table V).

X-Ray Crystallography The hydrochloride salt of 5a-5 was recrystallized from acetonitrile to give colorless columns. mp $145-147^{\circ} \mathrm{C}$. IR $(\mathrm{KBr}): 1595,1445,1250 \mathrm{~cm}^{-1} .{ }^{1} \mathrm{H}-\mathrm{NMR}\left(\mathrm{CD}_{3} \mathrm{OD}\right) \delta: 0.89(3 \mathrm{H}, \mathrm{t}$, $J=6 \mathrm{~Hz}, \mathrm{C}-\mathrm{Me}), 1.01-1.72\left(6 \mathrm{H}, \mathrm{m}, \mathrm{CH}_{2} \times 3\right), 2.42(3 \mathrm{H}, \mathrm{s}, \mathrm{SMe}), 3.88$ $\left(2 \mathrm{H}, \mathrm{t}, J=6 \mathrm{~Hz}, \mathrm{OCH}_{2}\right), 6.95-7.80(6 \mathrm{H}, \mathrm{m}, \mathrm{ArH}+$ imida $\mathrm{C} 4, \mathrm{C} 5-\mathrm{H})$, $7.22(1 \mathrm{H}, \mathrm{s},=\mathrm{CH}), 9.01(1 \mathrm{H}, \mathrm{t}, J=1 \mathrm{~Hz}$, imida $\mathrm{C} 2-\mathrm{H})$. Anal. Calcd for $\mathrm{C}_{17} \mathrm{H}_{22} \mathrm{~N}_{2} \mathrm{OS} \cdot \mathrm{HCl}: \mathrm{C}, 60.25 ; \mathrm{H}, 6.84 ; \mathrm{Cl}, 10.46 ; \mathrm{N}, 8.27 ; \mathrm{S}, 9.46$. Found: C. $60.17 ; \mathrm{H}, 6.78 ; \mathrm{Cl}, 10.55 ; \mathrm{N}, 8.25 ; \mathrm{S}, 9.20$.

Crystal data of this compound are listed in Table VII.

The lattice constants and intensity data were obtained on a Rigaku AFC-5 diffractometer using graphite-monochromated $\mathrm{Cu} K_{\alpha 1}$ radiation by $0-20$ scan method. A total of 3019 reflexions were measured within the $2 \theta$ of $120^{\circ}$. Intensity data were corrected for Lorentz and polarization factors, but no absorption correction was applied. The crystal structure was determined by the direct method using SAPI $85^{7)}$ and refined by the full-matrix last-squares method minimizing $F^{2}$. Hydrogen atoms were located from difference Fourier map except pentyl hydrogens. The final $R$ and $R_{w}$ were 0.074 and 0.105 , respectively, for 2634 reflexions with $F>F(\sigma)$, including anisotropic thermal parameters for non-hydrogen atoms and isotropic thermal parameters for hydrogen atoms. The ORTEP drawing is shown in Fig. 1 .

$(E)$-1-[1-(2-Hydroxyphenyl)-2-methoxyethenyl]-1 $H$-imidazole (10) A solution of Grignard reagent, prepared from 2-benzyloxy-bromobenzene
TABLE VII. Crystal Data of $5 \mathbf{a}-5 \cdot \mathbf{H C l}$

\begin{tabular}{|c|c|}
\hline $\begin{array}{l}\text { Formula } \\
\text { Formula weight } \\
\text { Crystal size } \\
\text { Space group } \\
\text { Cell dimension } \\
\\
\qquad F(0 \\
\\
\text { Calculated dens } \\
\text { Number of forn } \\
\text { Radiation and } \\
\text { Linear absorptic }\end{array}$ & $\begin{aligned} & \mathrm{C}_{17} \mathrm{H}_{23} \mathrm{ClN}_{2} \mathrm{OS} \\
& 338.90 \\
& 0.85 \times 0.35 \times 0.35 \mathrm{~mm} \\
& \text { Triclinic } P_{1}^{-} \\
& a= 9.729(2) \AA \\
& b= 13.309(2) \AA \\
& c= 8.703(4) \AA \\
& \alpha= 95.71(2)^{\circ} \\
& \beta= 109.05(3)^{\circ} \\
& \gamma= 114.90(1)^{\circ} \\
& V= 928.6(6) \AA^{3} \\
&00)= 360 \\
& \text { ty } D_{\mathrm{C}}=1.212 \mathrm{Mg} \mathrm{m}^{-3} \\
& \text { ula units } \quad Z=2 \\
& \text { avelength } \lambda\left(\mathrm{CuK}_{\alpha 1}\right)=1.5405 \AA \\
& \text { n coefficient } \quad \mu=2.839 \mathrm{~mm}^{-1}\end{aligned}$ \\
\hline
\end{tabular}

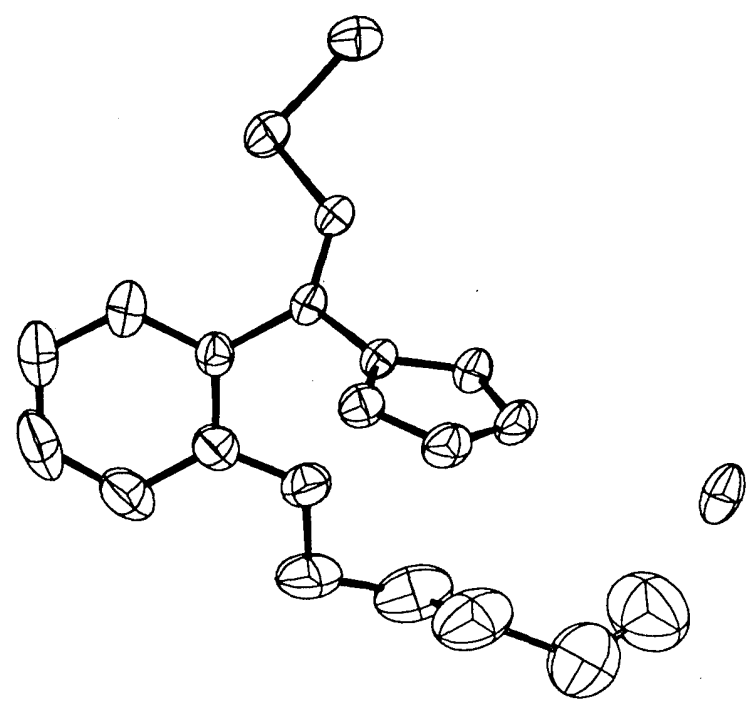

Fig. 1. ORTEP Drawing of $\mathbf{5 a}-5 \cdot \mathbf{H C l}$

$(7.90 \mathrm{~g})$ and magnesium $(0.73 \mathrm{~g})$ in dry THF $(4 \mathrm{ml})$, was added to a solution of methoxyacetonitrile $(1.90 \mathrm{~g})$ in dry THF $(20 \mathrm{ml})$ in an ice bath. Following the addition, the solution was stirred for $2 \mathrm{~h}$ at room temperature and poured into $1 \mathrm{~N}$ hydrochloric acid. Then the mixture was washed with ether, made alkaline with diluted ammonium hydroxide and extracted with ether. After removal of the solvent, $1 \mathrm{~N}$ hydrochloric acid was added to the residue, and the reaction mixture was refluxed for $30 \mathrm{~min}$, cooled to room temperature, and extracted with ether. The ether layer was dried over $\mathrm{MgSO}_{4}$, and evaporated under reduced pressure. The residue was distilled under reduced pressure to give 2 -benzyloxy-2methoxyacetophenone $(8,4.07 \mathrm{~g}, 56 \%)$ as colorless oil. bp 192-194 $(2 \mathrm{mmHg})$. MS $m / z: 256\left(\mathrm{M}^{+}\right)$. IR $(\mathrm{NaCl}): 1680 \mathrm{~cm}^{-1} \cdot{ }^{1} \mathrm{H}-\mathrm{NMR}\left(\mathrm{CDCl}_{3}\right)$ $\delta: 3.45(3 \mathrm{H}, \mathrm{s}, \mathrm{OMe}), 4.67\left(2 \mathrm{H}, \mathrm{s}, \mathrm{COCH}_{2}\right), 5.24\left(2 \mathrm{H}, \mathrm{s}, \mathrm{OCH}_{2}\right)$, $6.70-8.10(9 \mathrm{H}, \mathrm{m}, \mathrm{ArH})$.

The reaction mixture of $8(0.40 \mathrm{~g})$, Pd-black $(0.1 \mathrm{~g})$ in ethanol $(30 \mathrm{ml})$ was stirred for $1 \mathrm{~h}$ at hydrogen atmosphere. Then the catalyst was filtered off, and the filtrate was evaporated under reduced pressure. The residue was chromatographed (chloroform), to give 2'-hydroxy-2-methoxyacetophenone $(9,0.25 \mathrm{~g}, 96 \%)$ as colorless oil. MS $\mathrm{m} / \mathrm{z}: 166\left(\mathrm{M}^{+}\right)$. IR $(\mathrm{NaCl}): 1650 \mathrm{~cm}^{-1} \cdot{ }^{1} \mathrm{H}-\mathrm{NMR}\left(\mathrm{CDCl}_{3}\right) \delta: 3.50(3 \mathrm{H}, \mathrm{s}, \mathrm{OMe}), 4.68(2 \mathrm{H}$ $\left.\mathrm{s}, \mathrm{COCH}_{2}\right), 6.69-7.77(4 \mathrm{H}, \mathrm{m}, \mathrm{ArH}), 11.96(1 \mathrm{H}, \mathrm{s}, \mathrm{OH})$.

Thionyl chloride $(0.73 \mathrm{~g})$ was added to a stirred suspension of imidazole $(1.67 \mathrm{~g})$ in dichloromethane $(10 \mathrm{ml})$ in an ice bath; then reaction mixture was stirred for $30 \mathrm{~min}$ at room temperature. Then a solution of $9(0.68 \mathrm{~g})$ in dichloromethane $(5 \mathrm{ml})$ was added to the above solution in an ice bath. The reaction mixture was stirred for $1 \mathrm{~h}$ at room temperature, washed with water and dried over $\mathrm{MgSO}_{4}$. After removal of the solvent under reduced pressure, the residue was recrystallized from $\mathrm{MeOH}$ to give $\mathbf{1 0}$ $(0.63 \mathrm{~g}, 72 \%)$ as colorless needles. mp $200-203^{\circ} \mathrm{C}$ (dec.). IR ( $\mathrm{KBr}$ ): 1450, $1225 \mathrm{~cm}^{-1} .{ }^{1} \mathrm{H}-\mathrm{NMR}\left(\mathrm{CD}_{3} \mathrm{OD}\right): 3.77(3 \mathrm{H}, \mathrm{s}, \mathrm{OMe}), 6.59(1 \mathrm{H}, \mathrm{s}$, 
$=\mathrm{CH}), 6.68-7.35(6 \mathrm{H}, \mathrm{m}, \mathrm{ArH}+$ imida $\mathrm{C} 4, \mathrm{C} 5-\mathrm{H}), 7.65(1 \mathrm{H}$, br s, C2-H). High resolution MS: Calcd for $\mathrm{C}_{12} \mathrm{H}_{12} \mathrm{~N}_{2} \mathrm{O}_{2}$ : 216.0899. Found: 216.0929 .

Acknowledgement The authors are grateful to the staff members of the central analytical center of Tokyo College of Pharmacy for the elemental analysis.

\section{References}

1) H. Yamaguchi, Jpn. J. Med. Mycol., 26, 116 (1985).

2) M. Ogata, H. Matsumoto, Y. Hamada, M. Takehara, and K. Tawara, J. Med. Chem., 26, 768 (1983).

3) M. Ogata, H. Matsumoto, S. Kida, and S. Shimizu, Tetrahedron Lett., 1979, 5011.

4) M. Ogata, H. Matsumoto, S. Shimizu, S. Kida, M. Shiro, and K.
Tawara, J. Med. Chem., 30, 1348 (1987)

5) a) T. Asaoka, R. Kawahara, and A. Iwasa, Chemotherapy, 38, 753 (1990); b) Idem, ibid., 38, 769 (1990); c) K. Maebashi, T. Hiratani, K. Uchida, Y. Asagi, and H. Yamaguchi, Jpn. J. Med. Mycol., 31, 333 (1990); d) K. Maebashi, T. Hiratani, Y. Asagi, and H. Yamaguchi, ibid., 31, 343 (1990); e) Y. Nishiyama, K. Maebashi, Y. Asagi, T. Hiratani, H. Yamaguchi, N. Yamada, A. Taki, J. X. Rong, and M. Osumi, ibid., 32, 43 (1991).

6) J. M. Van Cutsem and D. Thienpont, Chemotherapy, 17, 392 (1972).

7) J. Yao, Z. Chao-de, J. Qian, F. Han, Y. Gu, and H. Fan, "SAPI85: A Computer Program for Automatic Solution of Crystal Structures from X-ray Data," Institute of Physics, Academia Sinica, Beijing' China, 1985. 